[1.r-10]

دور الالتزاتمات الأخلاقية لمهنة المحاسبة في تحسين أداء

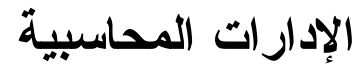

در اسة حالة في جامعة الموصل المداد

\author{
تغريد سالم الليلة \\ مدرس مساعد - قسم المحاسبة

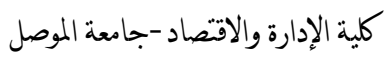

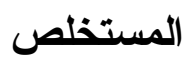

شغلت مسألة الأخلاق حيزاً كبيراً في الايانات السماوية فنجد في القرآن الكــريم أن الله

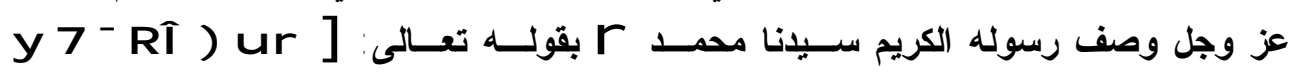

[ [50̈ œł t , @, Ë =\% 4 í n? y Ë s9
\end{abstract}

وتتجلى أهمية البحث من أهمية الاكتز امات الأخلاقية لمهنة المحاسبة في خلق محاسبين

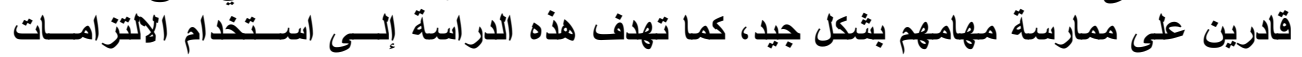

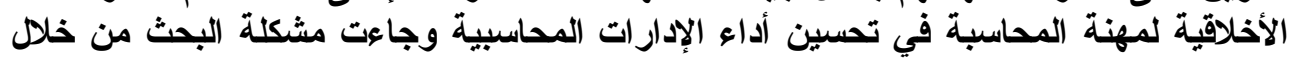

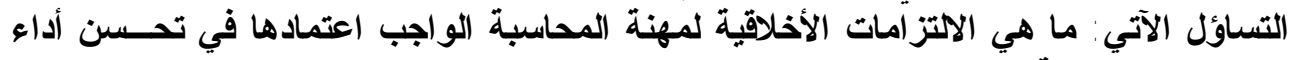
الإدارات المحاسبية: مائه

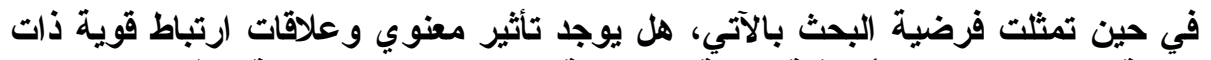

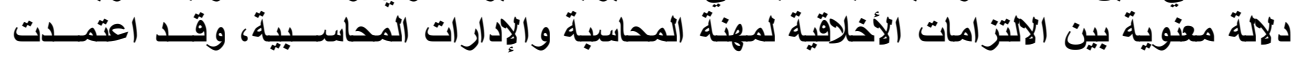

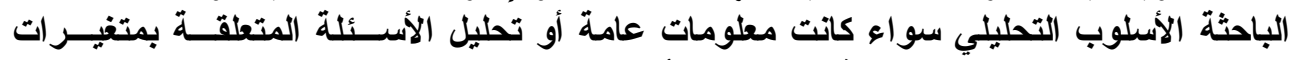

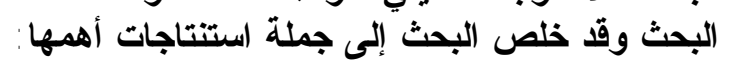
- إن الالتزام الأخلاقي من قبل ممارسي مهنة المحاسبة لابد من أن يقلل من تعـرض الإدارارات المحاسبية للخطر . الأبرام

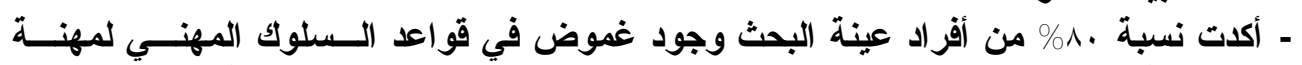

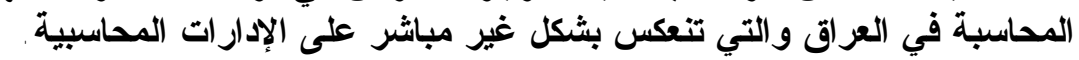




\title{
The Role of Ethical Obligations in Accounting Profession In Improve the Accounting Management Performance Case Study in Mosul University
}

\author{
Tagreed S. Al-Lila \\ Assistant Lecturer \\ Department of Accountancy \\ University of Mosul
}

\begin{abstract}
Ethics matter occupied a large scale in the divine studies. In Glorious Quran, it is seen that the Almighty Allah ascribes the Prophet Muhammad (PBUH) as "You are in great morals". The importance of the research comes from the importance of the ethical obligations of the accounting profession in creating financial managers to be able to do their tasks well. The study also aims to use ethical obligations of the accounting profession in activating the financial accountings. The problem of the research is confined to the following question, what are the ethical obligations of accounting profession that must be depended in activating the financial accounting? The hypothesis of the research is mentioned in the following form, are there abstract effect and drastic relationships - within the moral sense - between the ethical obligations of the accounting profession and the financial accounting. The research depends the analytical method in analyzing the information, whether general information, or the analyzing the questions concerning the research variables. The research concluded the following points:

-The ethical obligation of the practiced accounting profession must decrease the financial accounting faced the danger.

- Eighty percent (\%80) of the sample of the research emphasized that there is an ambiguity in the rules of the professional behavior of accounting profession in Iraq, which reflects directly on the financial accountings.

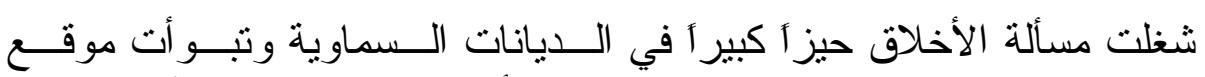

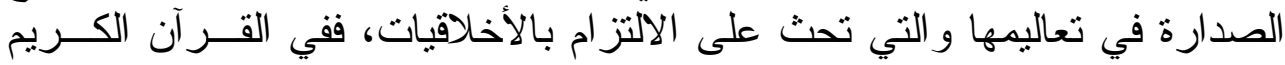

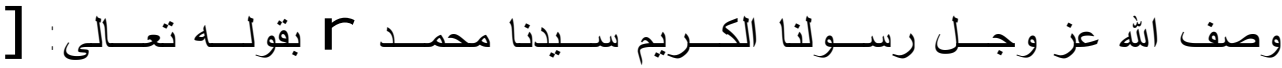

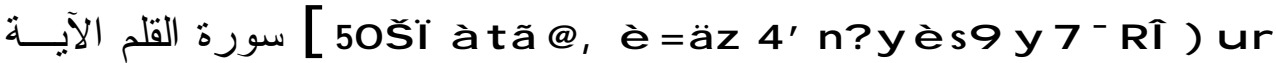

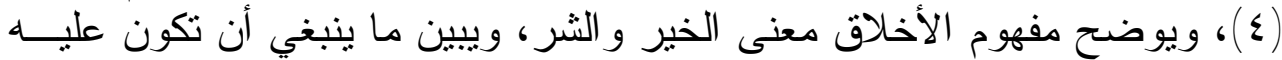

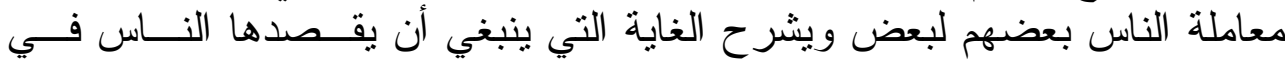

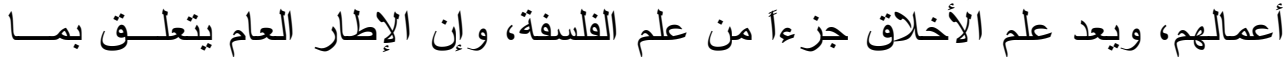

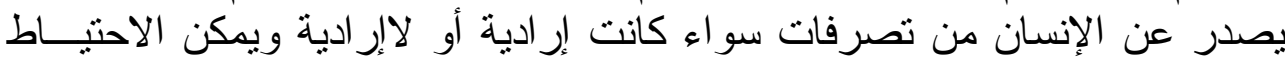

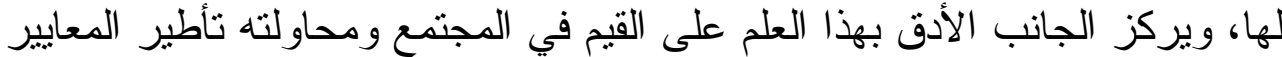
السلوكية الأخلاقية بما لا يتعارض مع الإطار العام وبما يخدم المنطلبات المتغيـــرة

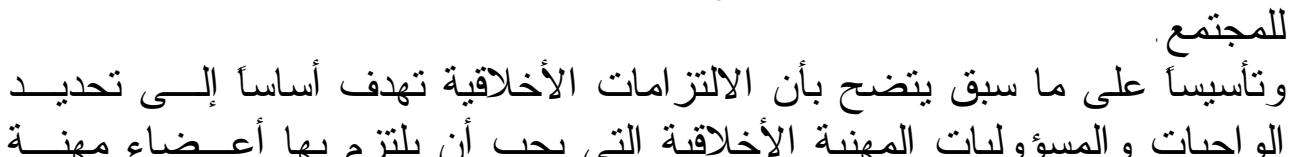


المحاسبة، فضلا عن أن المتطلبات الأخلاقية ينعكس أثرها ليس فقـــ علـــى أداء المحاسبين، بل ينعكس على أداء المحاسبين الماليين.

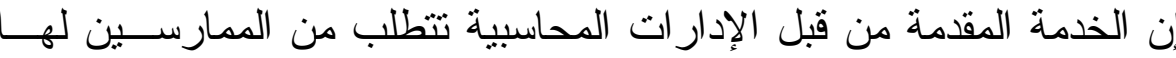

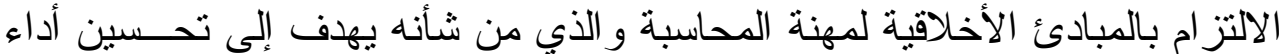
تلك الإدارات المحاسبية، فضلا عن انه يسهم في تحديد السبل الكفيلة برفع مستوى تلانه

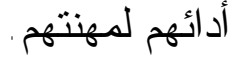

أهمية البحث

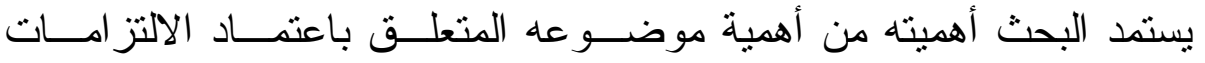
الأخلاقية في رفع كفاءة وتحسين أداء الإدار ات المحاسبية.

هاف البحث

ينحصر هدف البحث بالآتي:

بيان دور الالتز امات الأخلافية لمهنة المحاسبة فـي تحسين الألين أداء الإدارات المحاسبية، أما الأهداف الفر عية للبحث فتمتثل في الناحيتين الآتيتين: ا . بيان ماهية الالتز امات الأخلاقية لمهنة المحاسبة من حيث (المفهوم، الأهميـة،

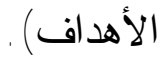
r r بيان موقف المنظمات الدولية و المحلية من الالتزامات الأخلاقية.

يفترض البحث فرضية أساسية مفادها الأتي:

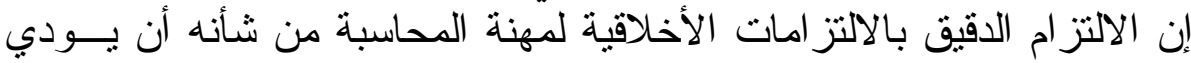

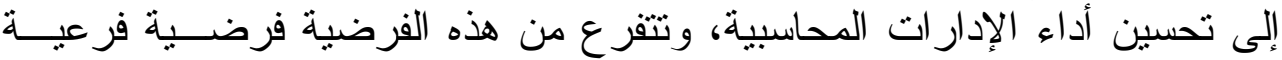

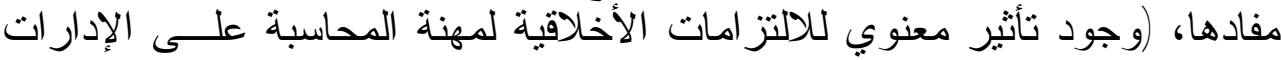

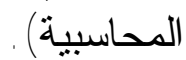

لما كان البحث يتكون من جانبين (نظري وتحليلي) فقد اعتمدت الباحثة على التى منهج البحث المنهجيين الآتيين لغرض البهن لإنمامه:

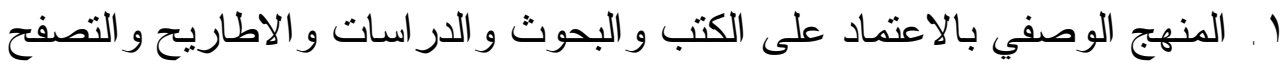

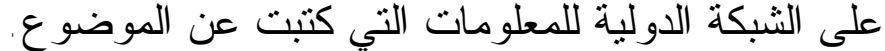

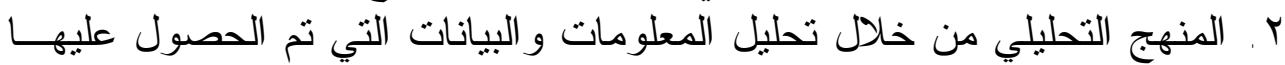

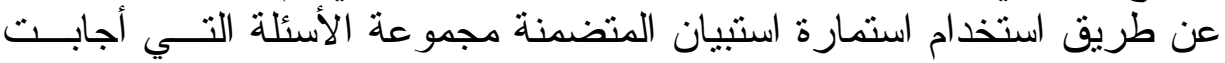


[^ی] الليلة

عليها عينة البحث و المتعلقة بالمعلومات الثخصية عن المبحوثين فضلا عـن المبن

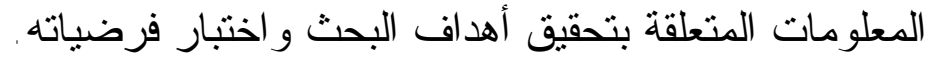

ماهية الاكتز امات الأخلاقية لمهنة المحاسبة

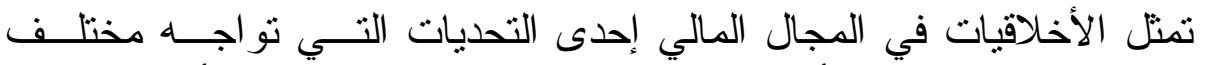

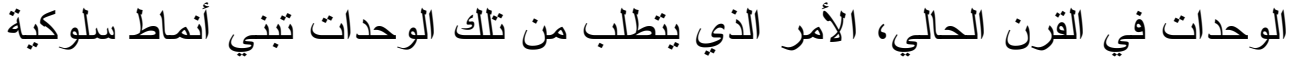
و أخلاقية في إعداد وصياغة في نتائجها المالية.

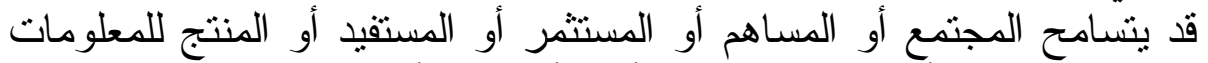

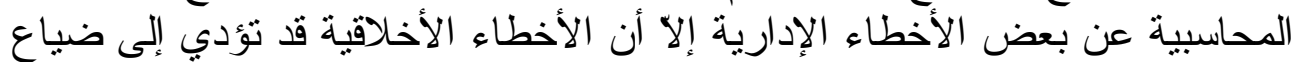

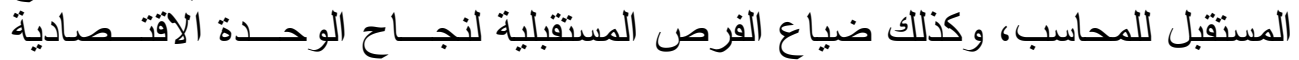

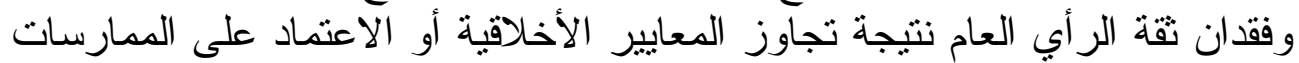
اللا أخلاقية في تحديد مسؤولية الإدارة المحاسبية تجاه الغير أو علاقتها بالمجتمع،

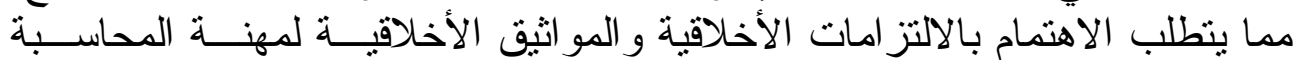

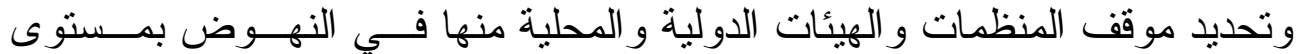
الإدار ات المحاسبية.

\section{أولاً - المفهوم والأهمية والأهد افت الأف

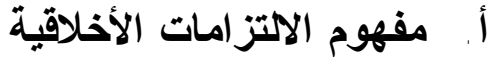

وردت العديد من التعاريف للالكتز امات الأخلافية الألية منها:

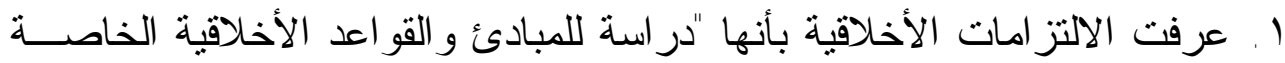

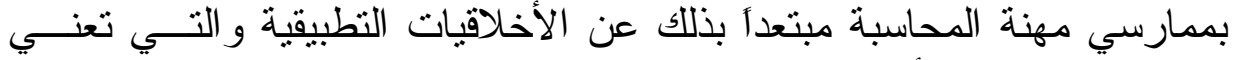

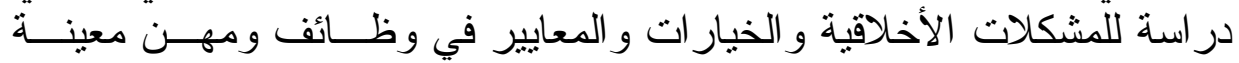

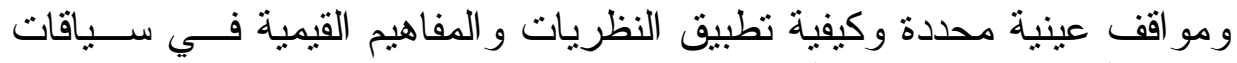

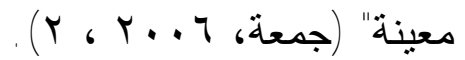

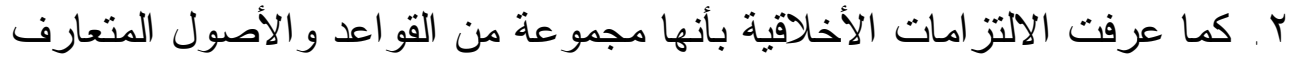

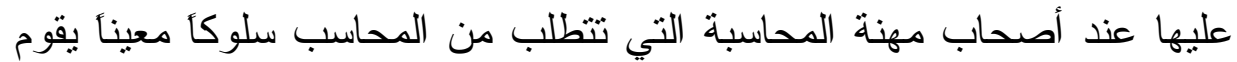

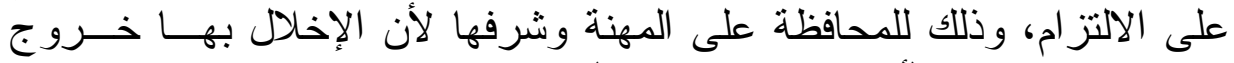

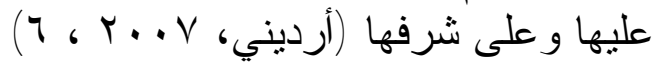

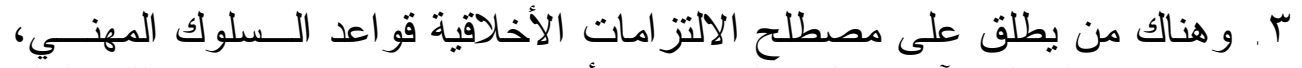

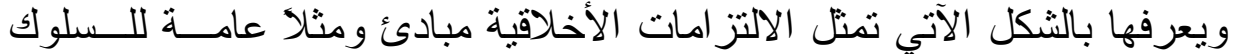

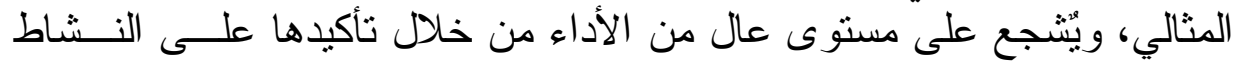

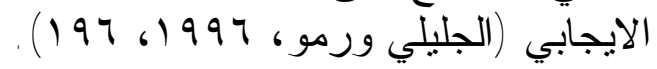

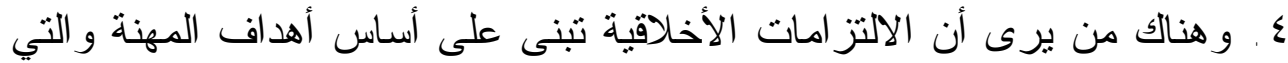

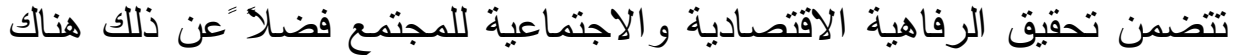

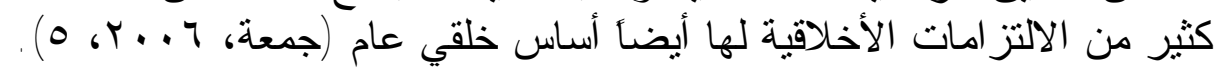




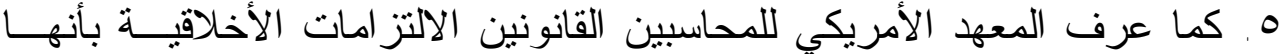

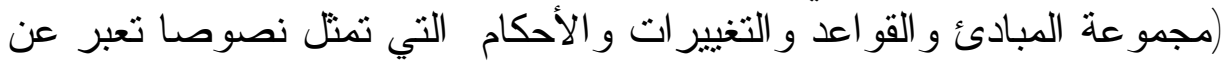

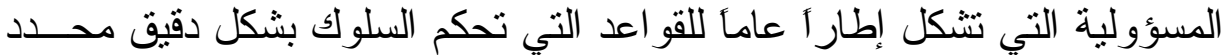

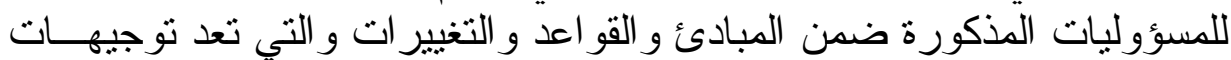

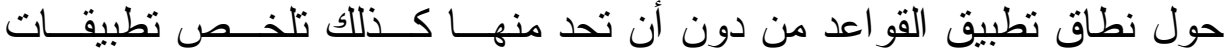

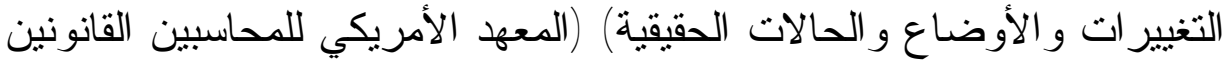
AICPA

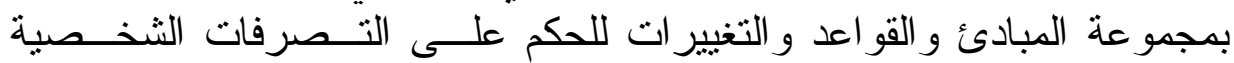

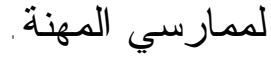
وييدي البعض بوجود نتاقض بين كل من النفع الثخصي وما تقتضيه المبادئ

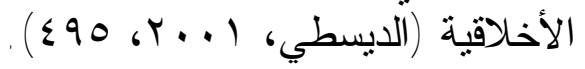

وييرز دور المنظمات و الهيئات المهنية المعنية بشؤون المحاسـبة فــــA الآتــي

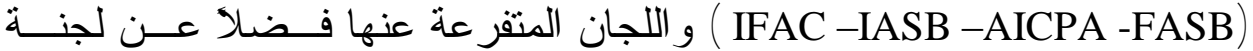

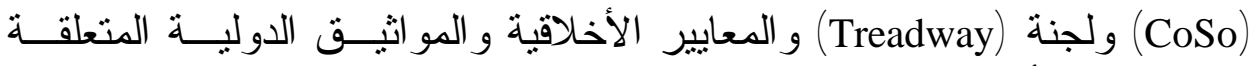

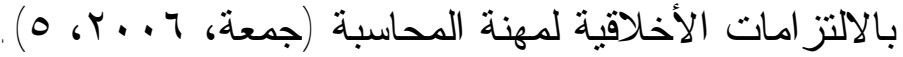

\section{ب. الأهمية، تتضح أهية البحث من خلا الآتي: (جمعة، ؟ . . ץ، ه)}

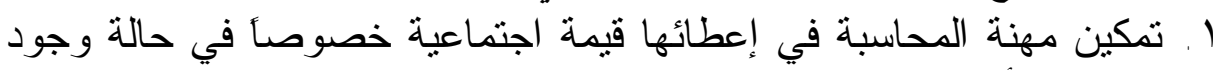
التز امات أخلاقية لدى المهنيين. r . مساعدة المحاسبين المهنيين في تحقيق جودة وكفاءة أدائهر لمهامهر و استبعاد

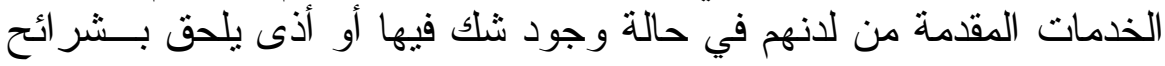

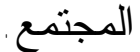
r. تمكين المهنة لاستيفاء معايير مهنية محاسبية. ع . تعزيز الثقة في أداء المهنيين في حالة تقديمهم للخدمات في إطار المسؤولية

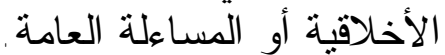

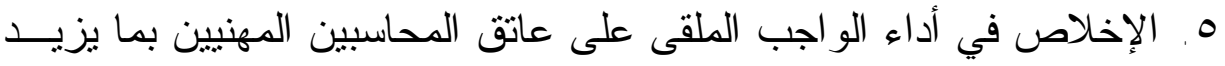
من ثنة الجمهور بمهنة المحاسبة. ويمكن أن تتحصر أهمية الالتز امات الأخلاقية بــالنواحي الآتبــة (الـــراوي، $:\left(\sum \Lambda\right.$, r... V

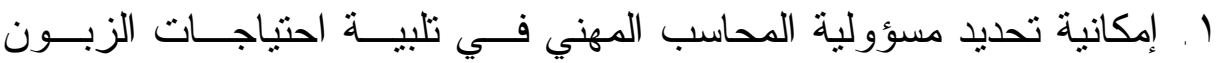

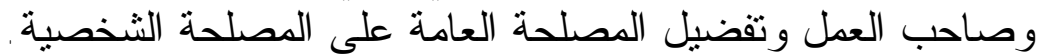

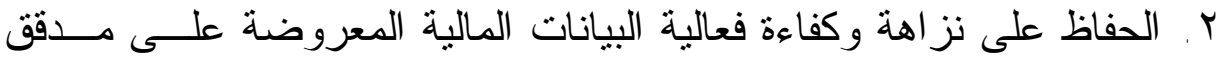

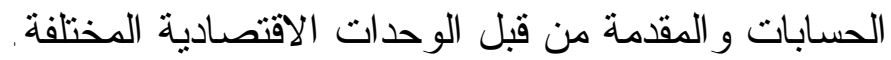

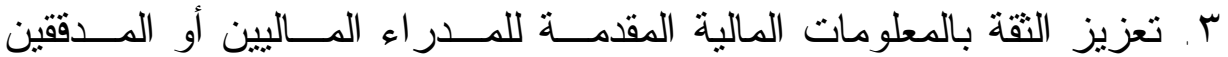
الداخليين أو خبراء الضريبة أو أي جهة أخرى يهمها أمر الوحدة. 


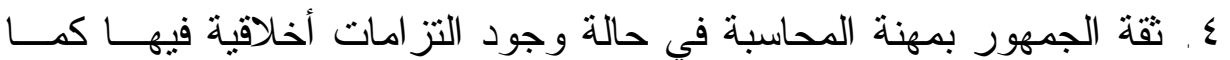

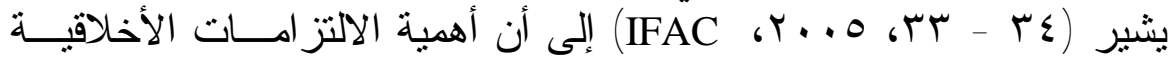

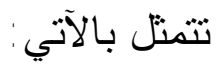

1 أمانة المحاسبين المهنيين وتحديد مسؤوليتهم تجاه مهنة المحاسبة.

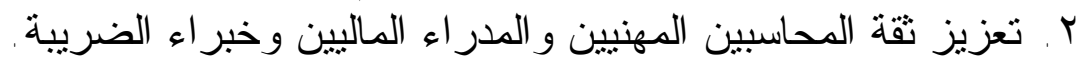

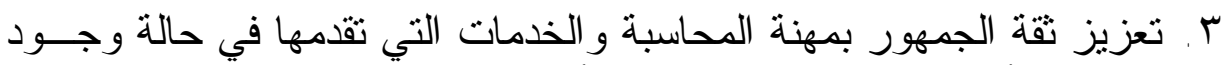

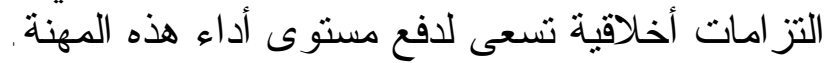

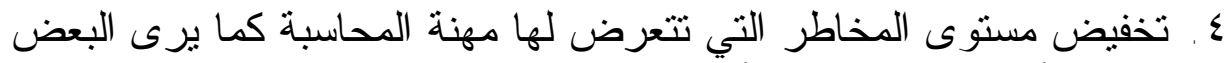

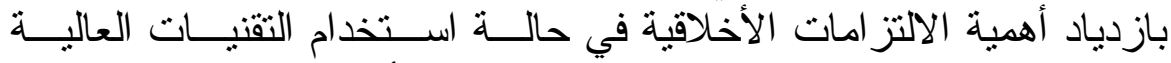

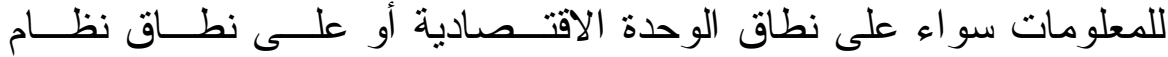

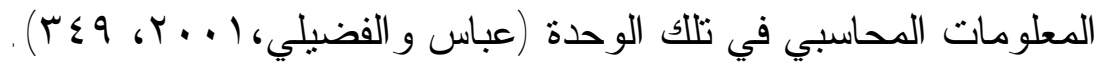

تهدف الالتزامات الأخلاقية إلى تحقيق الأغر اض الآتية:

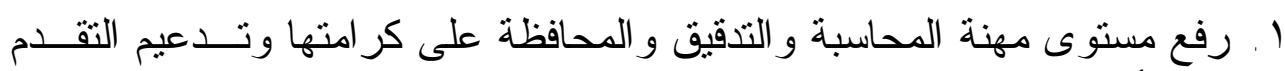
الذي أحرزته بين غيرها من المهن الحنة الحرة. r. تتمية روح التعاون بين المحاسبين و المدققين ور عاية مصالحهم المادية و الأدبية

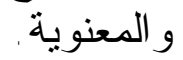
r. تدعيم وتكملة النصوص القانونية و الأحكام التي وضعها المشرع لتوفير مبدأي

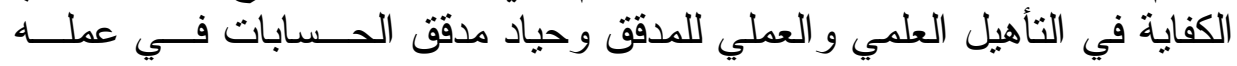

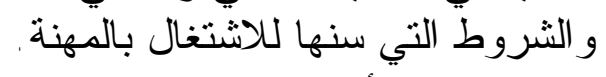

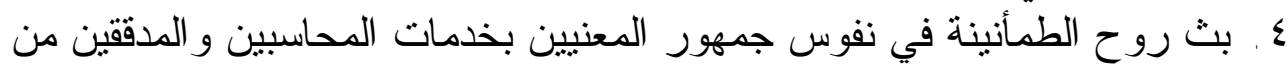
زبائن وغير هم من الجهات و والفئات المتعددة.

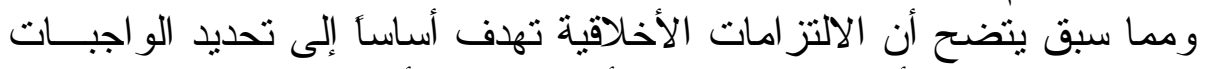

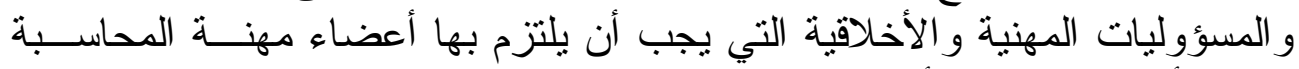

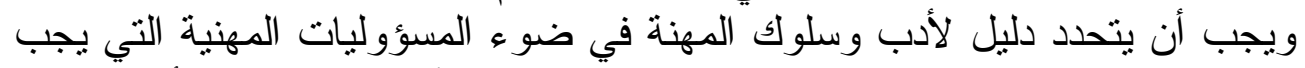

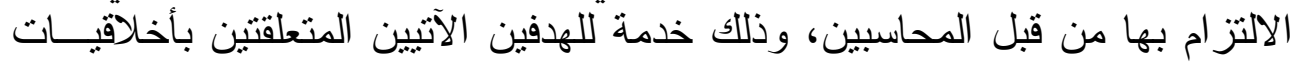

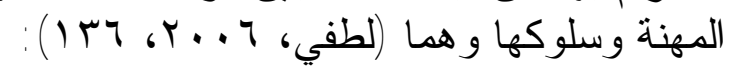

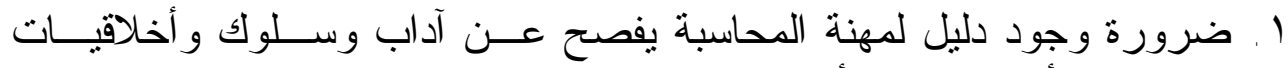

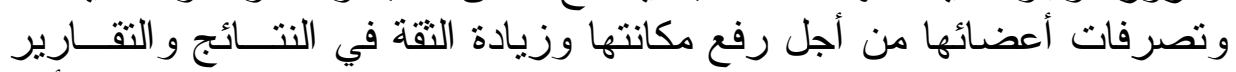

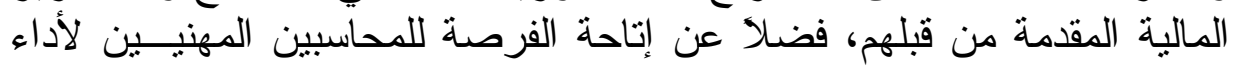

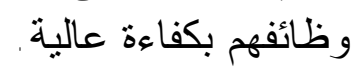

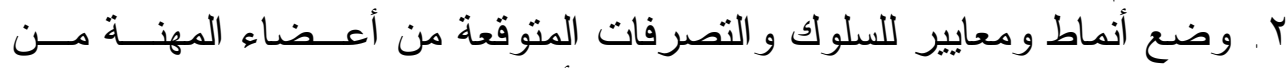

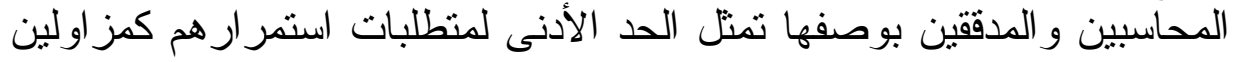
لعملهم المهني. 
موقف المنظمات الدولية والمحلية من الالتزامات الأخلاقية لمهنة المحاسبة

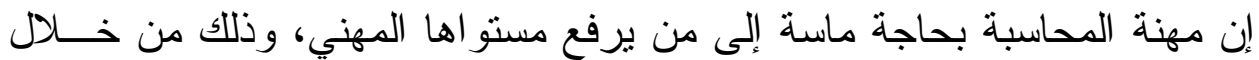

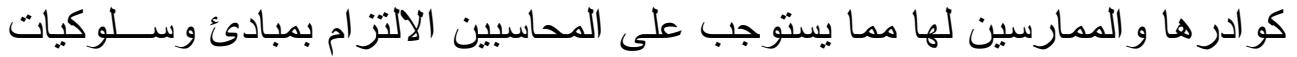

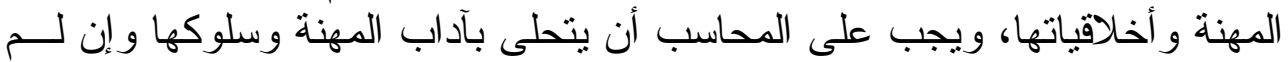

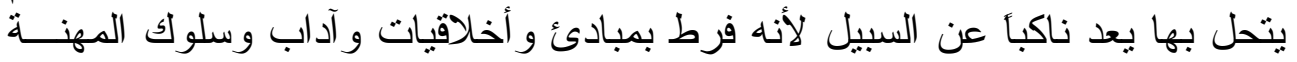

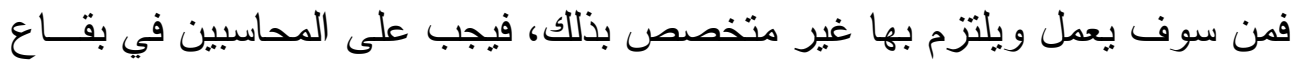

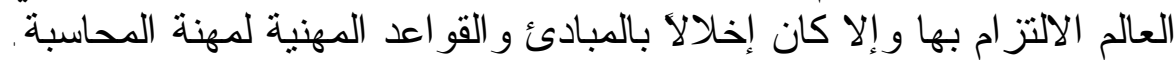
وينحصر موقف الهيئات و المنظمات الدولية و المحلية من الالنز امات الأخلاقية الإلية

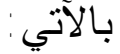

$$
\begin{aligned}
& \text { أ. تتظيم مهنة المحاسبة في ظل الالتز امات الأخلاقية } \\
& \text { ب. إصدار المعايير في الالتز امات الأخلافية }
\end{aligned}
$$

\section{أ. تنظيم مهنة المحاسبة في ظل الالتز امات الأخلاقية}

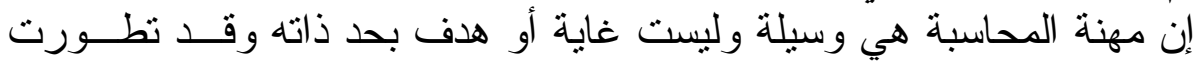

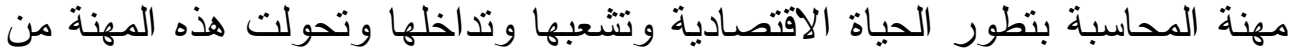

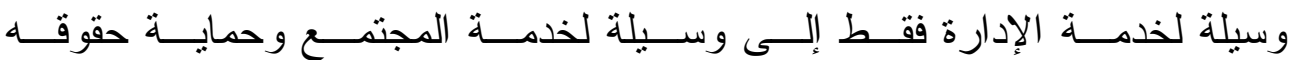

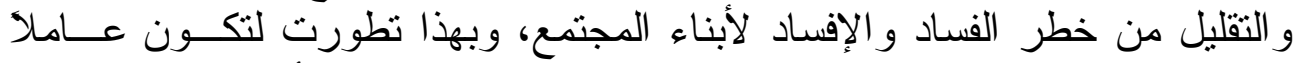

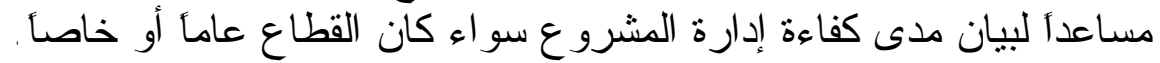

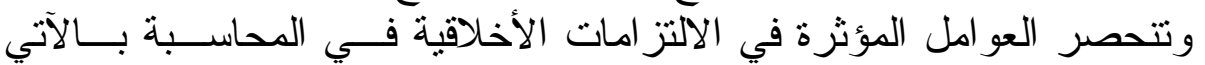

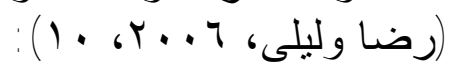

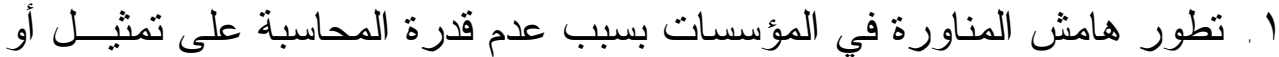

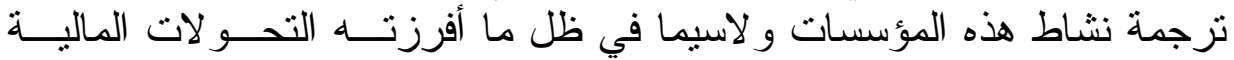

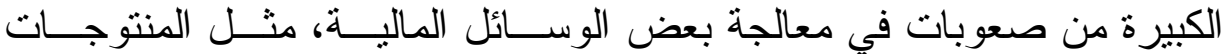

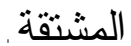
r . نتيجة لعدم تطابق المعايير المحاسبية مع منطلبات الأسو اق (خاصة المالية) منها

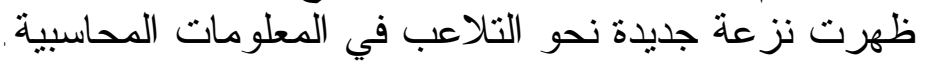

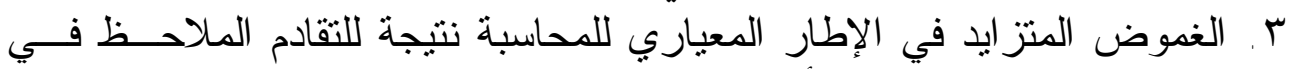

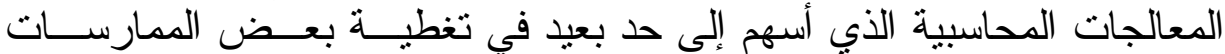

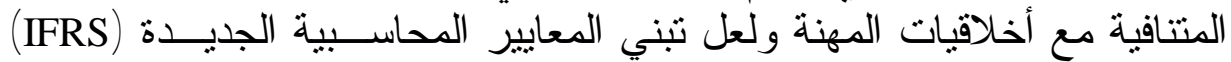

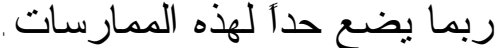

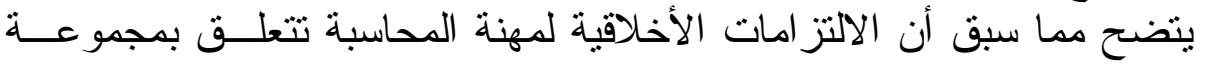

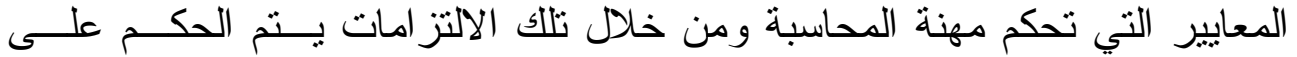

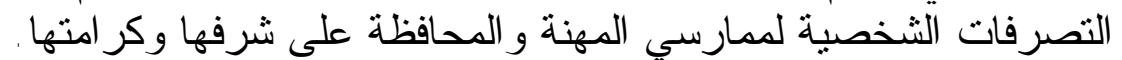

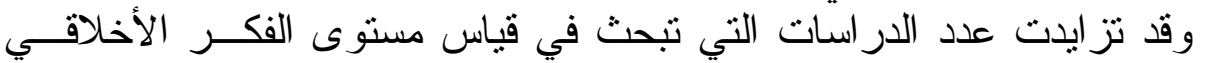

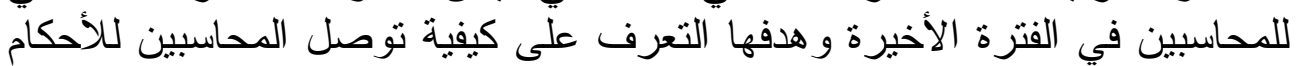

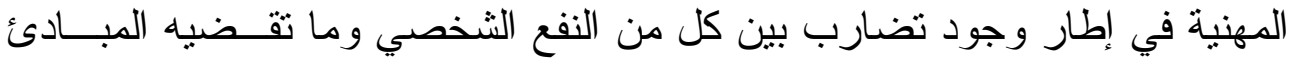




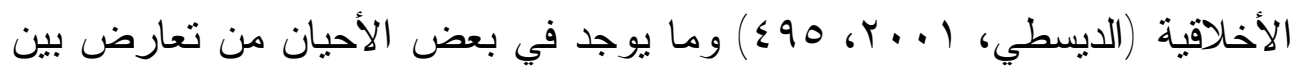

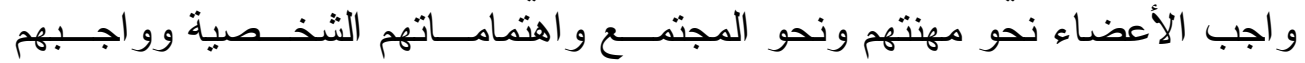

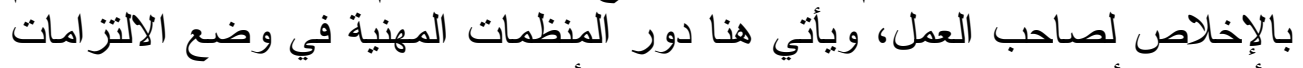

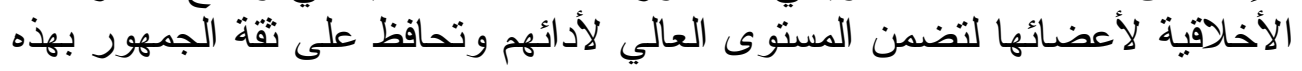

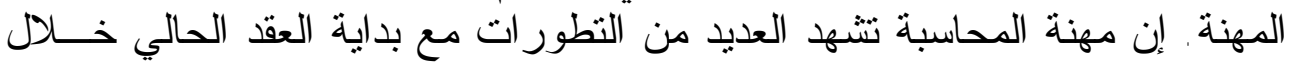

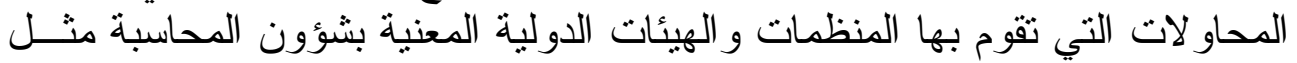

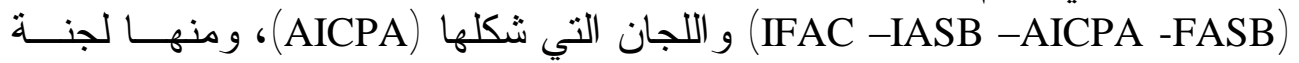

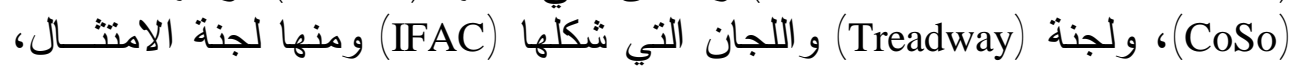

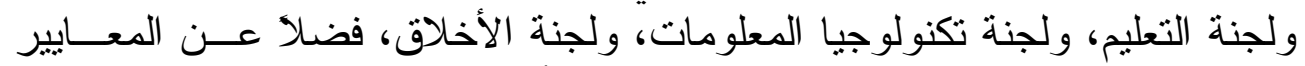

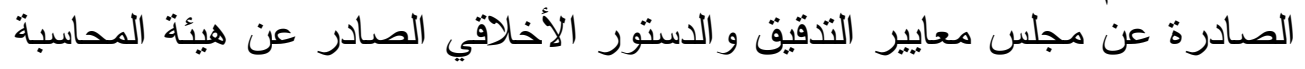

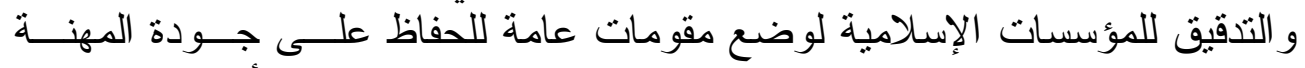

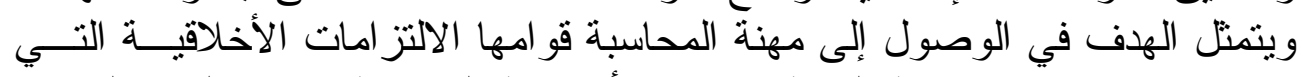

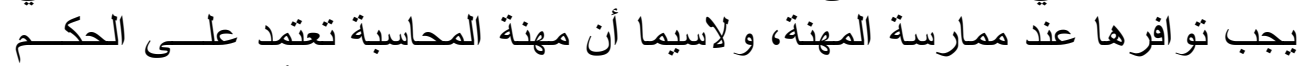

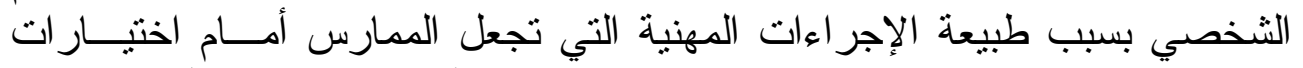

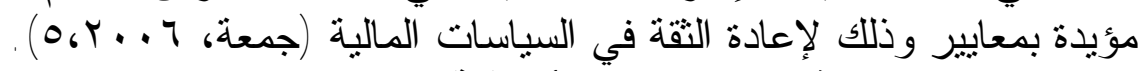

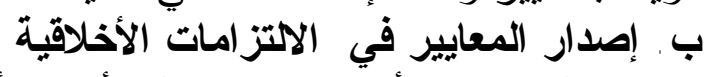

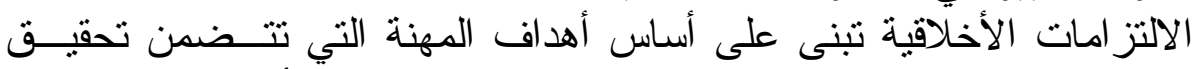

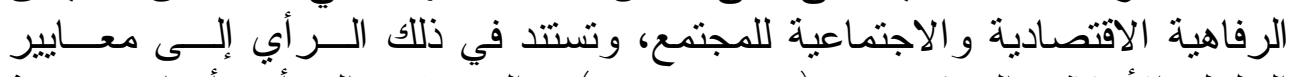

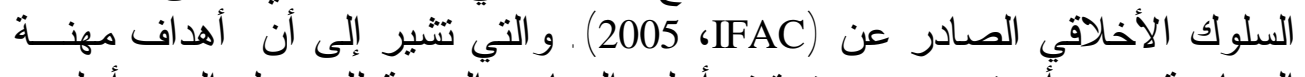

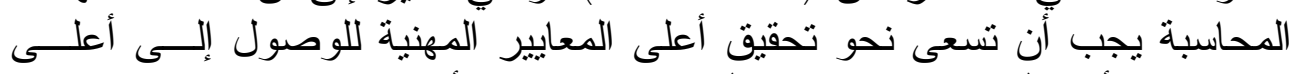

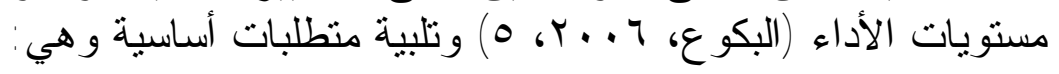

\section{أ. المصداقية}

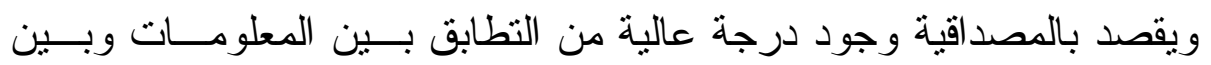

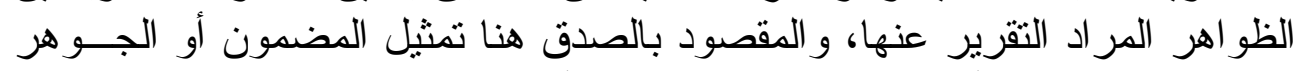

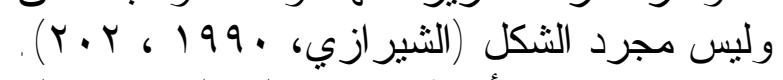

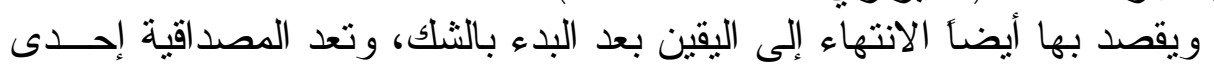

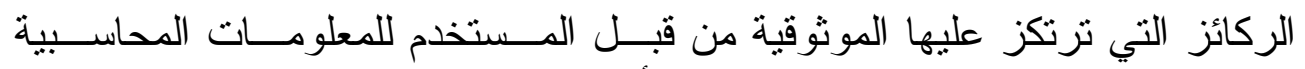

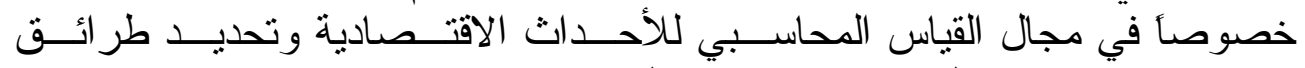

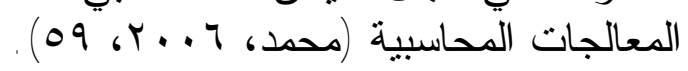

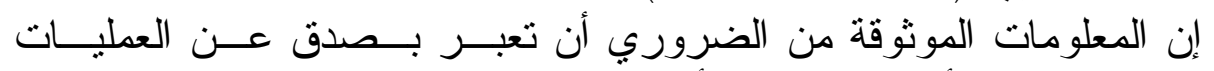

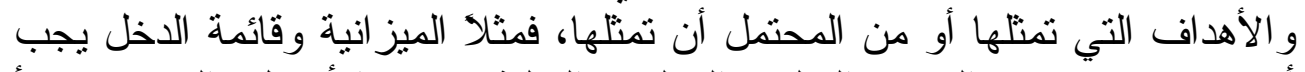

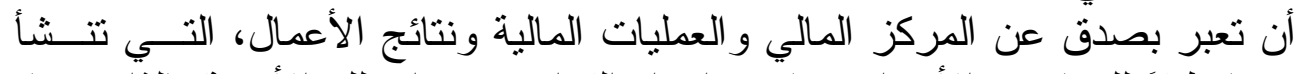

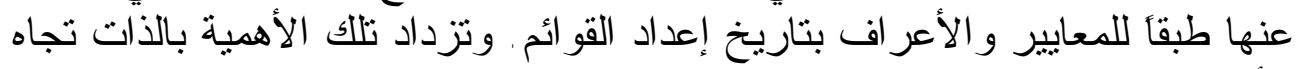

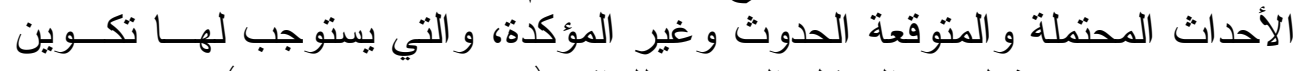

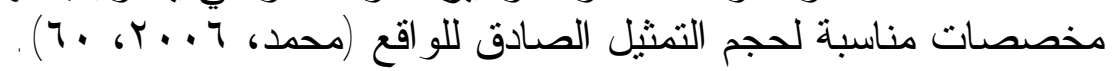




\section{Professionalism}

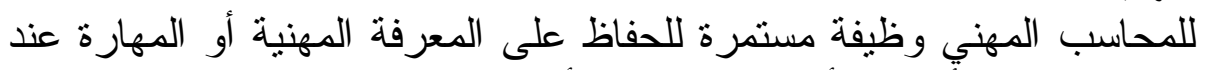

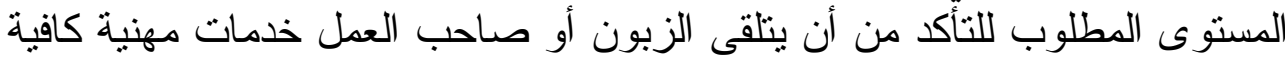

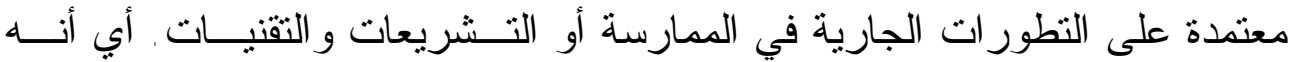

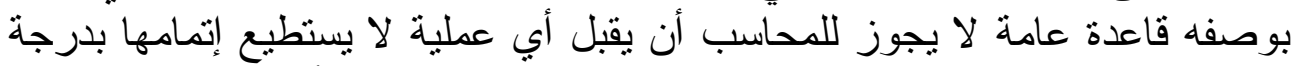

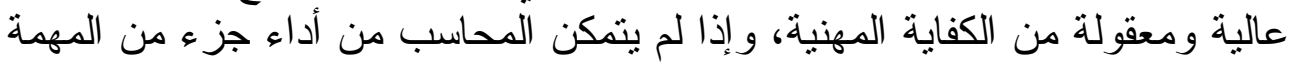

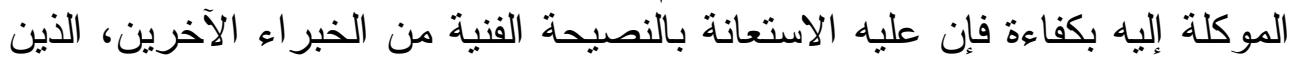

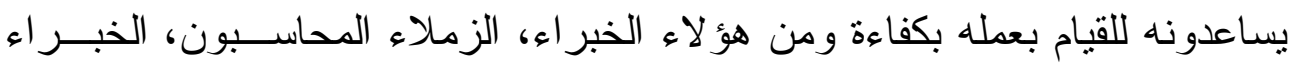

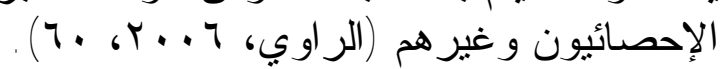

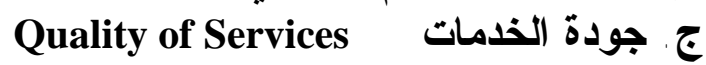

هناك حاجة للتأكد على أن الخدمات التي يقدمها المحاسبون المهنيون تتم طبقاً

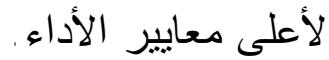

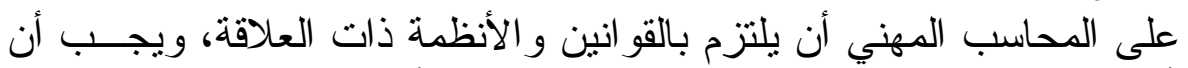

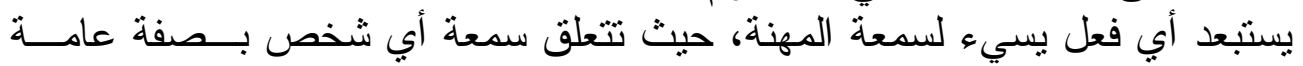

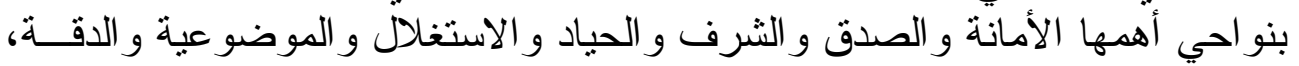

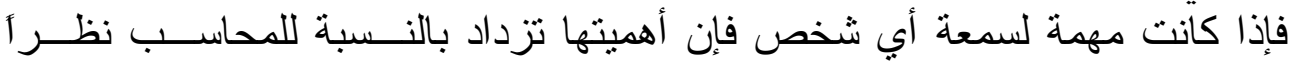

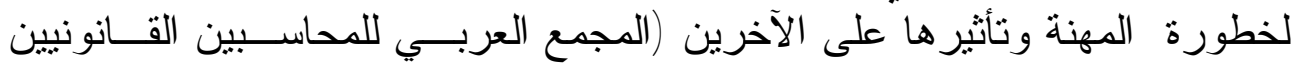

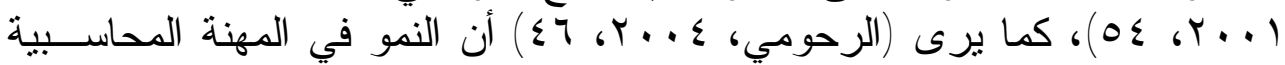
ينبغي أن يكون ناتجأ عن السمعة الجيدة وجودة البعاب الخدمة المقدمة.

\section{لد الثقة}

تعني قدرة المعلومات في التعبير عن فحوى الأهداف أو العمليات الاقتصادية

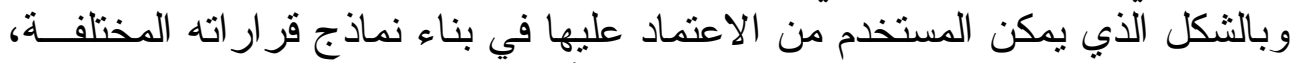

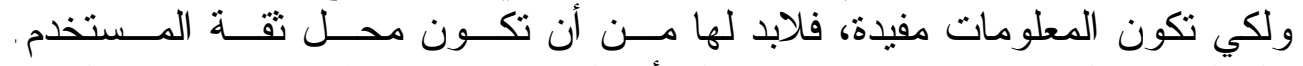

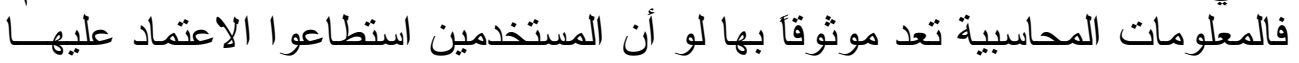

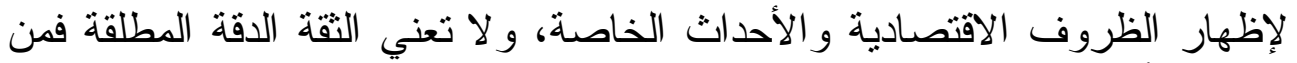

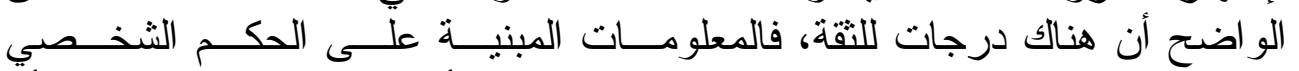

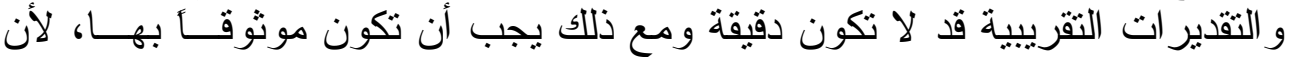

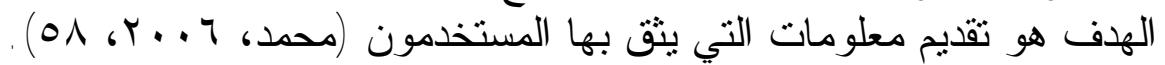

سبل تحسين أداء الإدارات المحاسبية في ضوء الالتزامات الأخلاقية

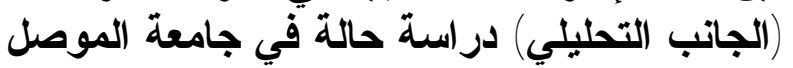

$$
\text { خصائص النتائجة الدراسة }
$$

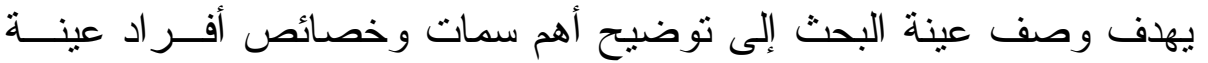

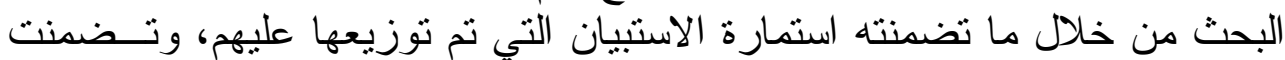

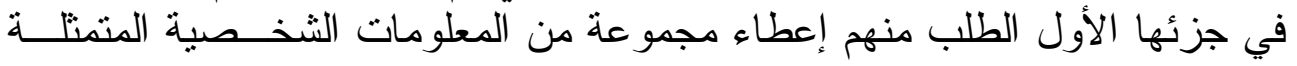




\section{الليلة [}

بالحالة العلمية وعدد سنوات الخدمة في مجال المحاسبة والتدقيق، و عنوان الوظيفة

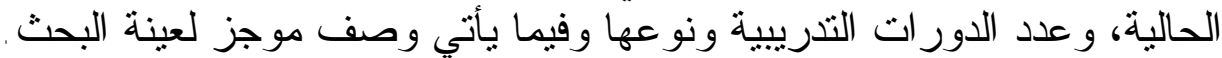

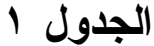

توزيع أفراد عينة البحث بحسب الحالة العلمية

\begin{tabular}{|c|c|c|}
\hline النسبة المئوية & العدد ال العد & التحصيل الدراسي \\
\hline$\% 1 r$ & $\varepsilon$ & إعدادية \\
\hline$\% 1 r$ & $\varepsilon$ & دبلوم فني \\
\hline$\% \mu r$ & 1. & بكالوريوس \\
\hline$\% \mu r$ & 1. & ماجستير \\
\hline$\% \wedge$ & $r$ & دكتور اه \\
\hline$\% 1 \ldots$ & $r$. & المجموع ع \\
\hline
\end{tabular}

و الجدول ا خاص بتوزيع أفر اد عينة البحث حسب الحالة العلمية و المؤهلات

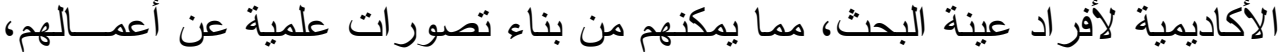

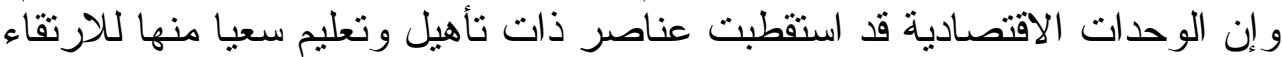

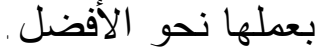

ا ـ عدد سنوات الخدمة في مجال المحاسبة والتدقيق

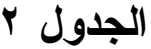

توزيع أفراد عينة البحث بحسب عداد سنوات المبات الخدمة

\begin{tabular}{|c|c|c|}
\hline النسبة المئوية & العدد & الفئات \\
\hline$\%$ & $r$ & | -9 سنة \\
\hline$\%$ \%r & $\bar{v}$ & •| -9 اسنة \\
\hline$\% \circ \mathrm{V}$ & IV & 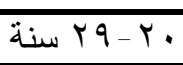 \\
\hline$\% 1$. & $r$ & 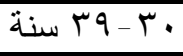 \\
\hline$\% 1 \ldots$ & $r$. & المجموع \\
\hline
\end{tabular}

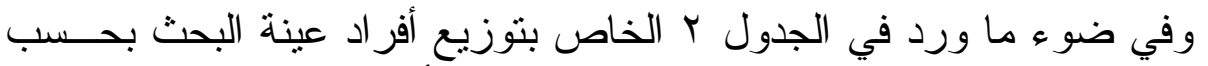

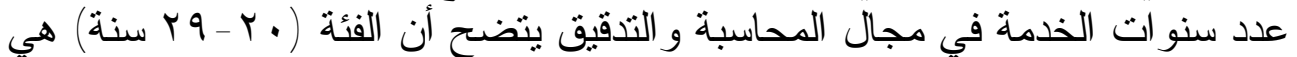

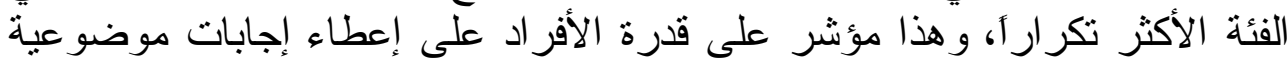

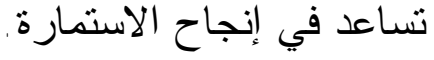




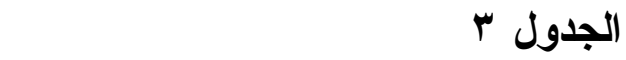

تحديد الدورات التدريبية بحسب أنواعها وأعدادها لأفر اد عينة البحث

\begin{tabular}{|c|c|}
\hline العدد & نوع الدورات \\
\hline 17 & محاسبية \\
\hline $1 \varepsilon$ & تققيقية و رقابية \\
\hline 1. & حاسبات \\
\hline 1. & إحصائية \\
\hline 15 & إدارية \\
\hline r & قانونية \\
\hline 70 & المجموع \\
\hline
\end{tabular}

من الجدول ب الخاص بتحديد الدور ات الندريبية بحسب أنو اعهــا و أعـــادها

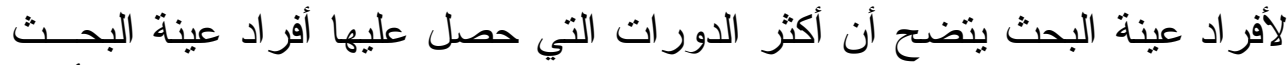

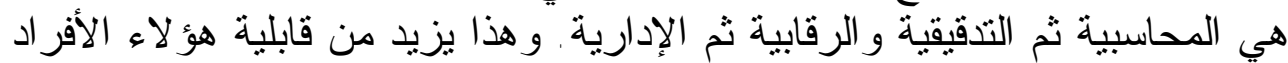

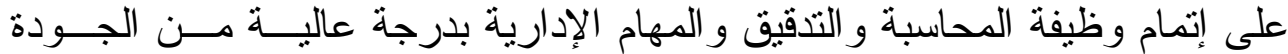

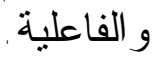

المحور الأول (الالتزامات الأخلاقية لمهنة المحاسبة)

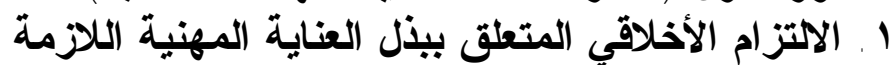

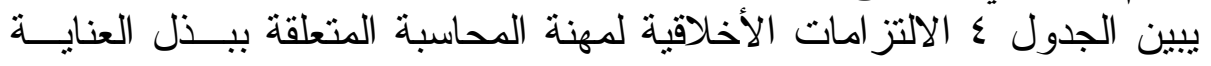

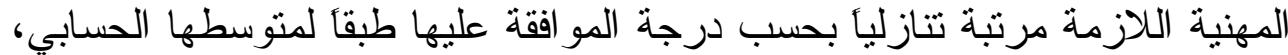

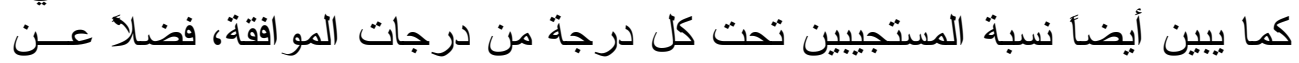
الانحر اف المعياري للإجابات لكل النز ام .

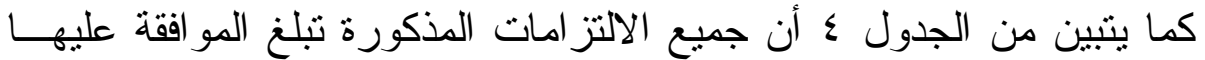

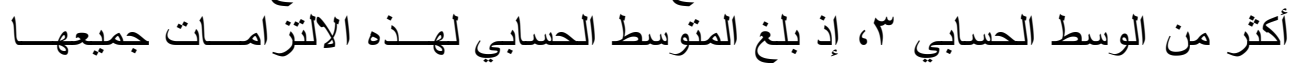
(r,YON)

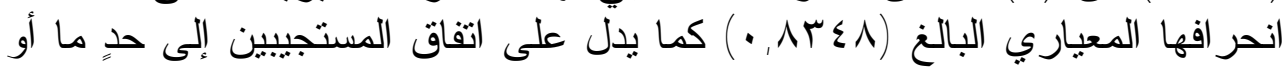

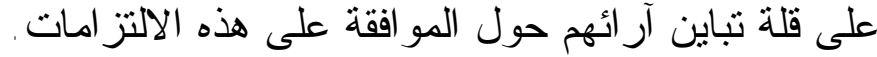


الليلة [94]

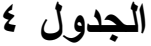

التوزيعات التكرارية والنسب المئوية والأوساط الحسابية والاحتر افات المعيارية الماتية للالتزامات الأخلاقية لمهنة المحاسبة المتعلقة ببذل العناية المهنية اللازمة الإية

\begin{tabular}{|c|c|c|c|c|c|c|c|c|c|c|c|c|}
\hline \multirow{2}{*}{ لِيرَ } & \multirow{2}{*}{ صنسائي } & \multicolumn{2}{|c|}{ بر بر فر } & \multicolumn{2}{|c|}{ نير دو لئي } & \multicolumn{2}{|c|}{ نهايد } & \multicolumn{2}{|c|}{ sily. } & \multicolumn{2}{|c|}{ she } & \multirow{2}{*}{ 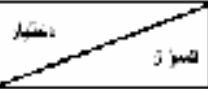 } \\
\hline & & w & IE & +6 & $3 x$ & 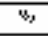 & 12 & w & ב & 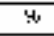 & בx & \\
\hline$\| \mathrm{rt} \cdots$ & ४।II & 1 & " & $\because ;$ & - & $4 \%$ & $\because$ & m: & $\because$ & $r \cdot i$ & $\therefore$ & 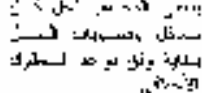 \\
\hline $0 \leq \mathrm{cr}:$ & $3 \mathrm{sic}$ & 3 & 0 & 0 & c & $\mathbf{3 0}$ & $\theta$ & 33 & iz & 6.5 & $i$ & 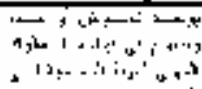 \\
\hline L.o'jis & 3.63 & 3 & 0 & $n$ & $\epsilon$ & 30 & $\sigma$ & $39 i$ & L & $2: 3$ & 7 & 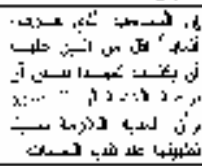 \\
\hline II & $i<\because$ & 1 & " & Al & $r$ & ㄴI & $n$ & 的。 & I & $8 \cdot$ & $\therefore$ & 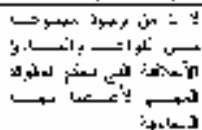 \\
\hline L.:18 & $3.2 \mathrm{~s}$ & $J$ & u & J1L & & I:2 & & $\sin 0$ & &.$c .5$ & & ח \\
\hline
\end{tabular}

كما يتبين من الجدول ع أن أكثر الالتزامات الأخلاقية أهمية لمهنة المحاسبة

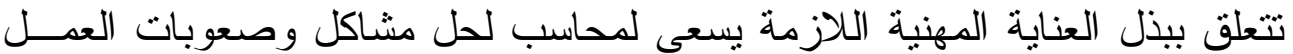

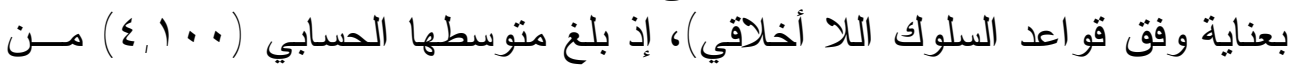

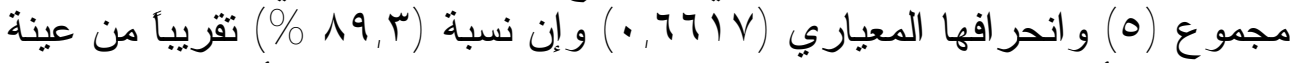

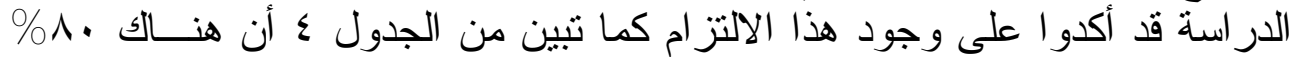

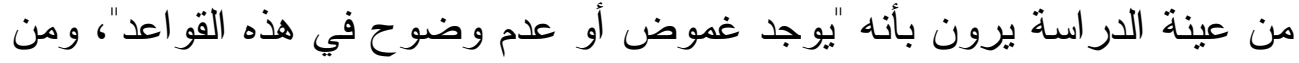
ثم يؤدي إلى صعوبة تطبيقها من قبل المحاسبين. 


\section{- الجدول}

التوزيعات التكرارية والنسب المئوية والأوساط الحسابية والاحتر افات المعيارية للالتز امات الأخلاقية لمهنة المحاسبة المتعلقة (بالمصداقية)

\begin{tabular}{|c|c|c|c|c|c|c|c|c|c|c|c|c|}
\hline \multirow{2}{*}{ 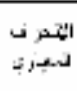 } & \multirow{2}{*}{ لموند } & \multicolumn{2}{|c|}{ 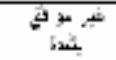 } & \multicolumn{2}{|c|}{ 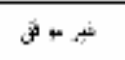 } & \multicolumn{2}{|c|}{ عبل } & \multicolumn{2}{|c|}{ بالو } & \multicolumn{2}{|c|}{ رالق بعة } & \multirow[t]{2}{*}{3} \\
\hline & & 4 & 4 & $\%$ & $a$ & $\vec{A}$ & 4 & 4 & $a$ & $\%$ & 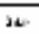 & \\
\hline 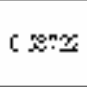 & 4 & 3.2 & 1 & J & J & $x$ & $s$ & $t C$ & $: 8$ & $13 ?$ & 5 & 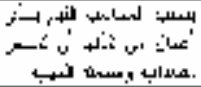 \\
\hline$c 528$ & $3.8 \mathrm{c} 6$ & c & J & 167 & $s$ & $: 3$ & נכ & $4 \$ 7$ & .4 & 3.2 & - & 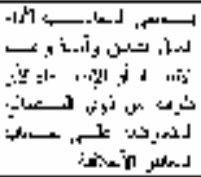 \\
\hline 1.40 & $\because 1 .+n$ & 1 & 1 & si & ' & if" & $i$ & 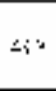 & $" s$ & $1 \%$ & 2 & 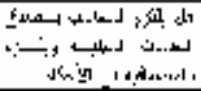 \\
\hline $.75 \div$ & 3.60 & 10 & 3 & 33 & ? & li.T & 5 & 80.7 & $\cdots$ & 133 & 1 & 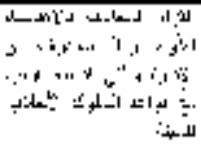 \\
\hline $6: 908$ & 3.824 & 3.22 & & 158 & & $32 ?$ & & 45.7 & & 13 & & "تهـلـ \\
\hline
\end{tabular}

\section{r r الالتزام الأخلاقي المتعلق بالمصداقية الإن}

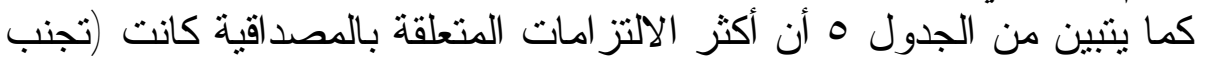

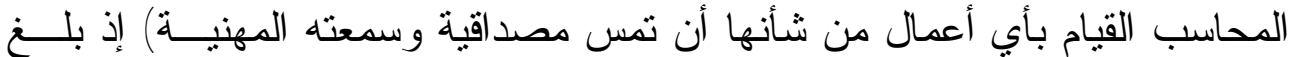

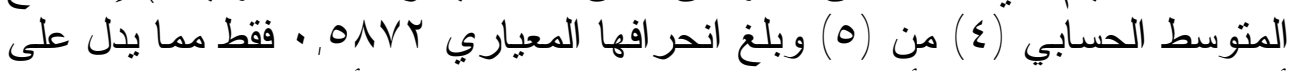

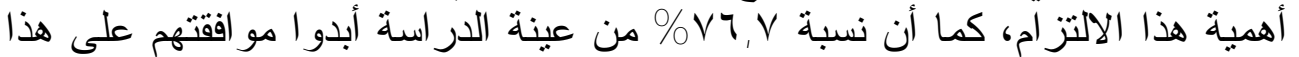

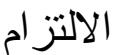

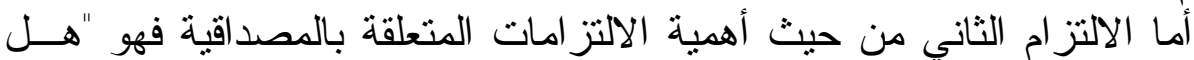

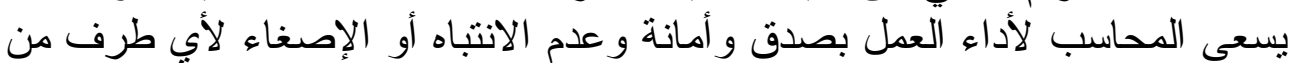

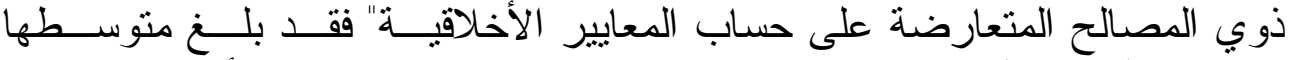

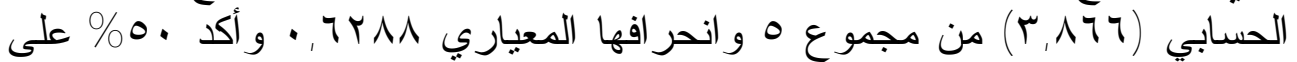

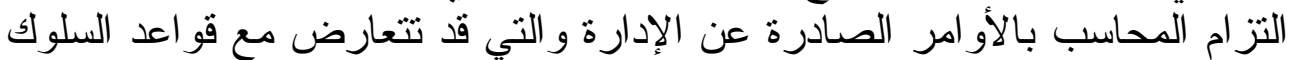

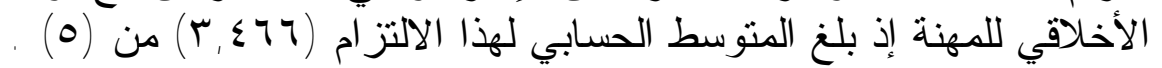




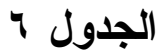

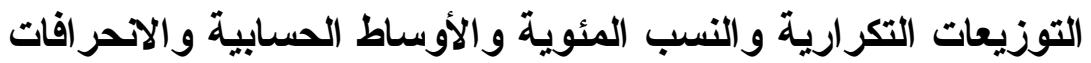

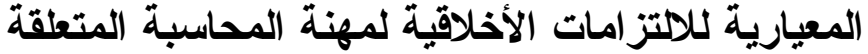

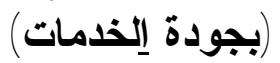

\begin{tabular}{|c|c|c|c|c|c|c|c|c|c|c|c|c|}
\hline \multirow{2}{*}{ 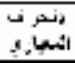 } & \multirow{2}{*}{ 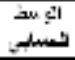 } & \multicolumn{2}{|c|}{ 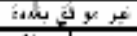 } & \multicolumn{2}{|c|}{ ث } & \multicolumn{2}{|c|}{4} & \multicolumn{2}{|c|}{$f y$} & \multicolumn{2}{|c|}{$\sin 4$ fis: } & \multirow{2}{*}{ 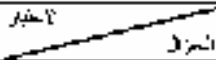 } \\
\hline & & $\%$ & ش & $x$ & ש & $\bar{y}$ & $\bar{i}$ & $\bar{x}$ & ش & $\bar{x}$ & تذد & \\
\hline$r: 32$ & - & $r$ & 1 & 1 & n & If, 7 & 5 & min & $\pi$ & If. 7 & 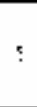 & 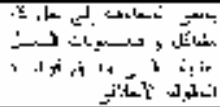 \\
\hline $1 . \therefore 12$ & $\{.4$ & 1 & 1 & $\because 3$ & 4 & $\because{ }^{\prime}$ & :: & ו' & 18 & " & 1 & 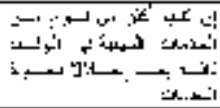 \\
\hline r.PI4 & 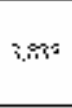 & 3.3 & 1 & 1 & n & $x$ & $\dot{n}$ & $m a$ & if & 1.3 & $\therefore$ & 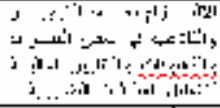 \\
\hline 1.m. & 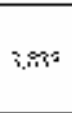 & r & 1 & $\bar{n}_{2}, 7$ & 2 & $1: 3$ & 4 & ריה & $\because$ & $\cdot n$ & $=$ & 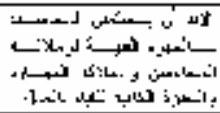 \\
\hline 7710 & ingif & 185 & & $i$ & & 15. & & si: & & $\pi$ & & $x_{1}^{3-y_{1}}$ \\
\hline
\end{tabular}

r. الاتتزام الأخلاقي المتعلق بجودة الخدمات

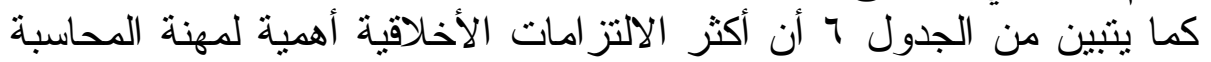

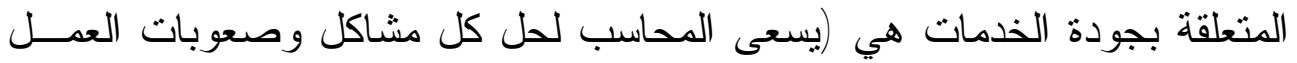

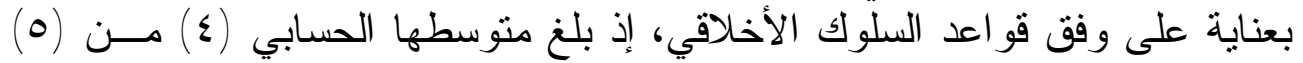

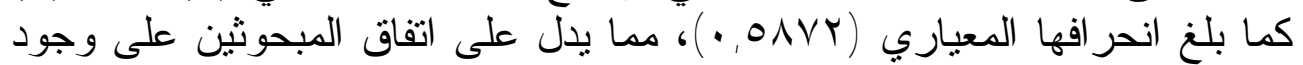

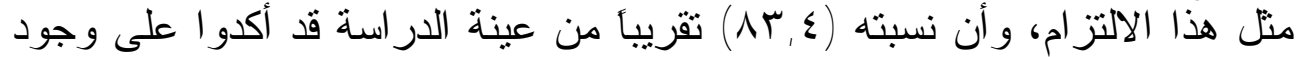

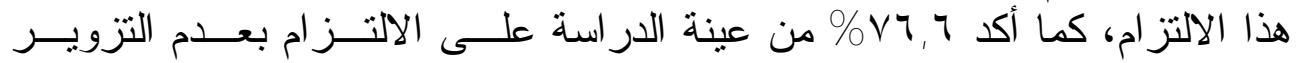

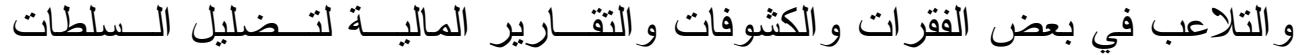

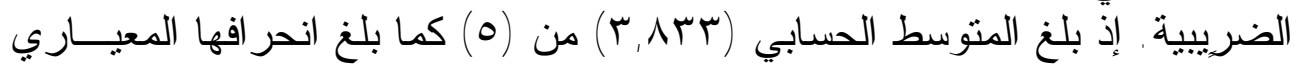
$(\cdot, \sqrt{ },(1) \varepsilon)$

ثانياً - الإدارات المحاسبية

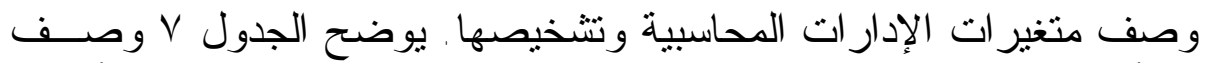

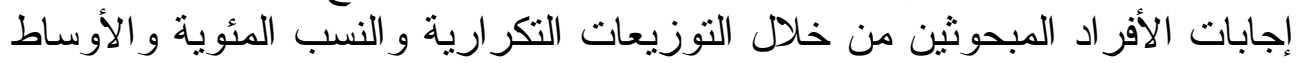

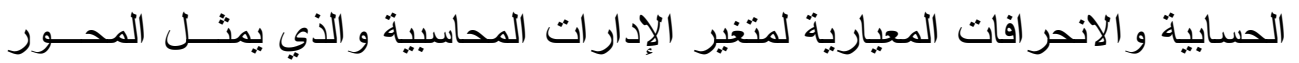

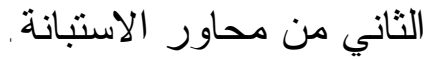




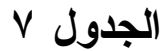

التوزيعات التكرارية و النسب المئوية والأوساط الحسابية والاحمر افات

المعيارية للإدارات المحاسبية الإسياط

\begin{tabular}{|c|c|c|c|c|c|c|c|c|c|c|c|c|}
\hline \multirow{2}{*}{ الإحبرزئ } & \multirow{2}{*}{ لصنيف } & \multicolumn{2}{|c|}{ 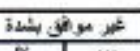 } & \multicolumn{2}{|c|}{ gor } & \multicolumn{2}{|c|}{ 4د } & \multicolumn{2}{|c|}{ 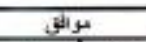 } & \multicolumn{2}{|c|}{ ر } & \multirow{2}{*}{ Jis } \\
\hline & & 8 & \pm & $\overline{\mathrm{s}}$ & \pm & $\%$ & 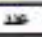 & $\%$ & $\Delta$ & $\%$ & E & \\
\hline 0.6288 & 3.866 & & 0 & 3.3 & 1 & 16.7 & 5 & 70 & 21 & 10 & 3 & 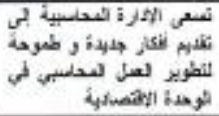 \\
\hline 0.4548 & 4 & & 0 & 0 & 0 & 10 & 3 & 80 & 24 & 10 & 3 & 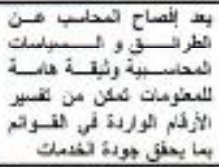 \\
\hline 0.3051 & 3.9000 & & 0 & 0 & 0 & 10 & 3 & 90 & 27 & 0 & 0 & 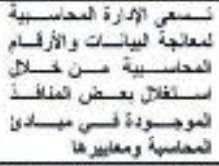 \\
\hline 0.1825 & 3.966 & & 0 & 0 & 0 & 3.3 & 1 & 96.7 & 29 & 0 & 0 & 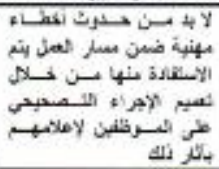 \\
\hline 0.4611 & 3.833 & & 0 & 0 & 0 & 20 & 6 & 76.7 & 23 & 3,3 & 1 & 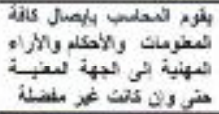 \\
\hline 0.8441 & 3.66 & 0 & 0 & 13,3 & 4 & 16.7 & 5 & 60 & 18 & 10 & 3 & 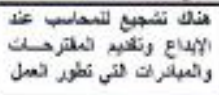 \\
\hline 0.7279 & 3.766 & 0 & 0 & 10 & 3 & 10 & 3 & 73.3 & 22 & 6.7 & 2 & 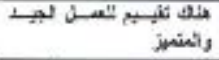 \\
\hline 0.6914 & 3.933 & 0 & 0 & 6.7 & 2 & 6.7 & 2 & 73.3 & 22 & 13.3 & 4 & 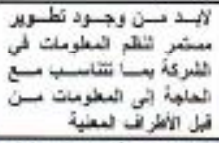 \\
\hline 0.4842 & 3.800 & 0 & 0 & 0 & $\theta$ & 23.3 & 7 & 73.3 & 22 & 3.3 & 1 & 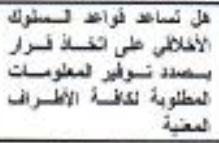 \\
\hline 0.5713 & 3.86 & 0 & 0 & 0 & 0 & 23.3 & 7 & 66.7 & 20 & 10 & 3 & 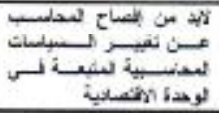 \\
\hline 0.776 & 3.86 & 0 & 0 & 10 & 3 & 6.7 & 2 & 70 & 21 & 13.3 & 4 & 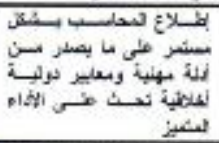 \\
\hline 1.118 & 3.3 & 0 & o & 36.7 & 11 & 10 & 3 & 40 & 12 & 13.3 & 4 & 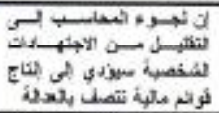 \\
\hline 0.8562 & 3.366 & 0 & 0 & 23.3 & 7 & 16 & 5 & 60 & 18 & 0 & 0 & 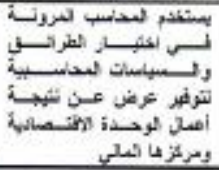 \\
\hline
\end{tabular}


الليلة [1...

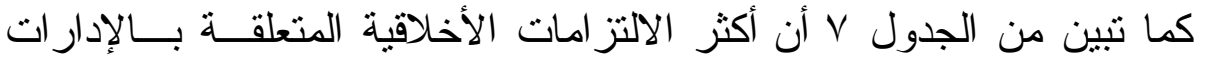

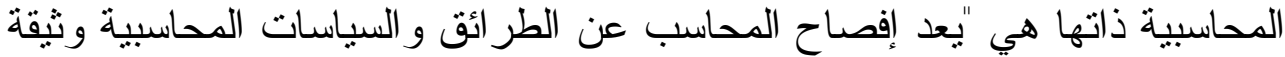

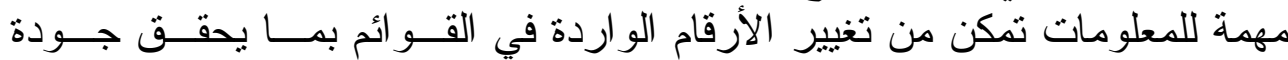

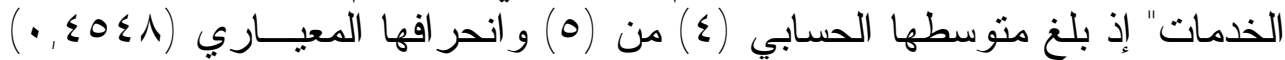

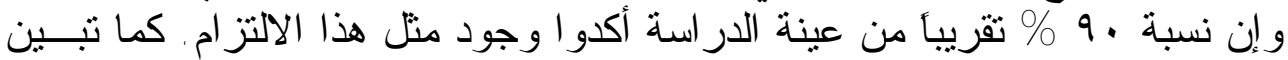

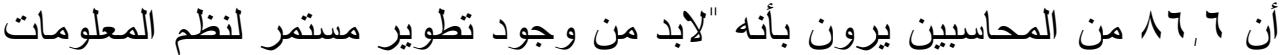

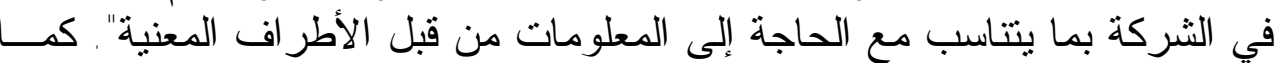

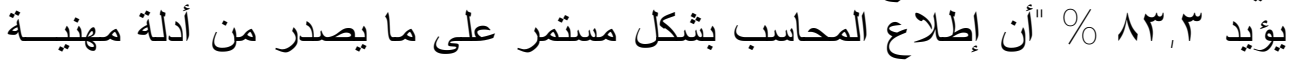

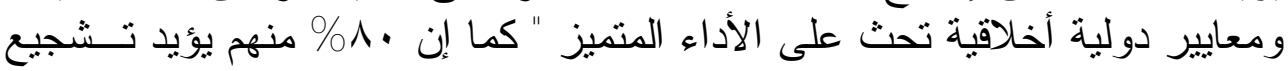

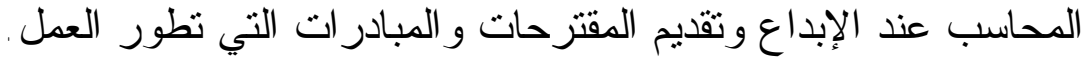

اختبار فرضية البحث

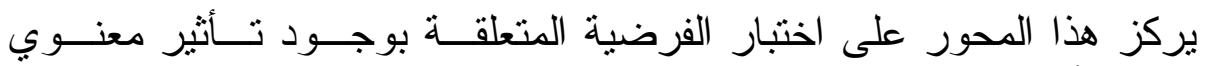

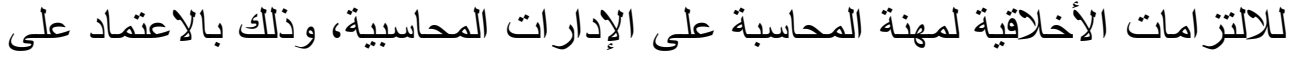

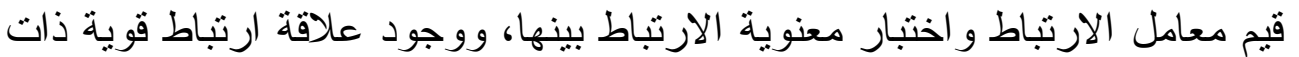

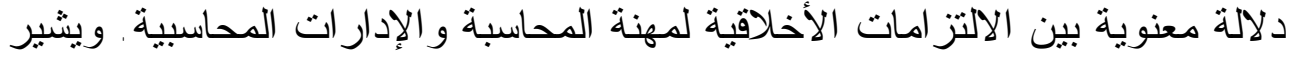

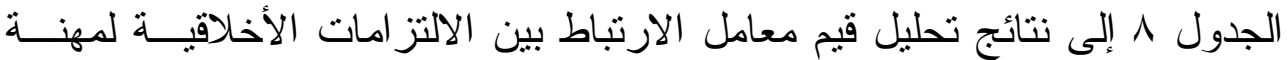

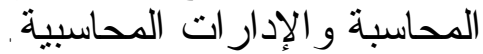

\begin{tabular}{|c|c|c|c|c|}
\hline \multicolumn{5}{|c|}{ * الجدول ^* } \\
\hline الارتباط الكلي & جودة الخدمات & المصد اقية & المهنية اللازيمة & الألتزلاقية \\
\hline $.6 \leqslant 00 *$ & $.677 . * *$ & .649 & .61 .0 & الإداسبية \\
\hline
\end{tabular}

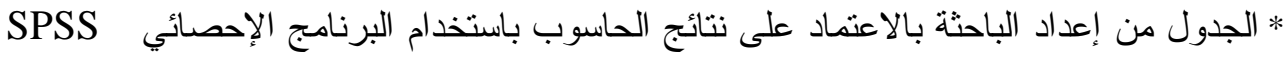
.version

ويوضح الجدول 1 نتائج تحليل الارتباط ويشير إلى وجود علاقات ارتبـاط الإناط

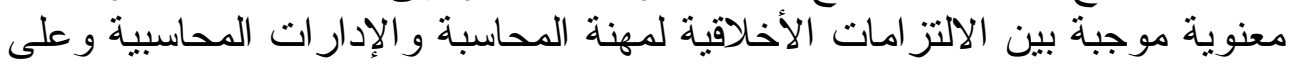

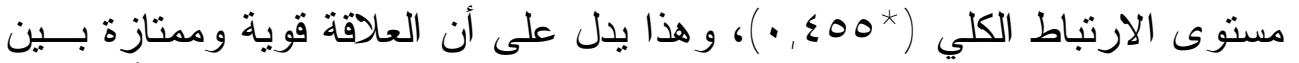

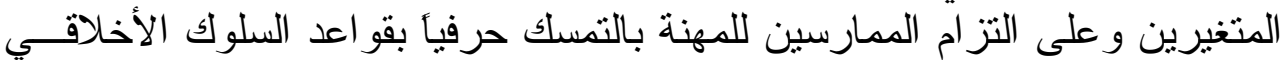

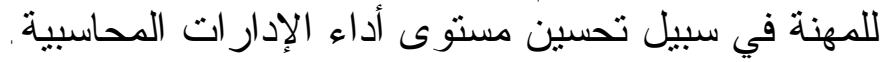
ويتضح من التحليل الآتي:

1ـ العلاقة بين الالتزام بيذل العناية المهنية اللازمة والإدارات المحاسبية

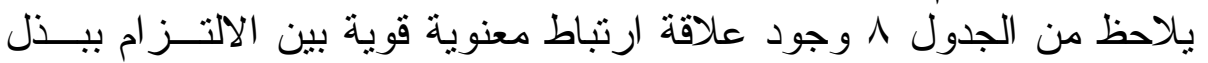

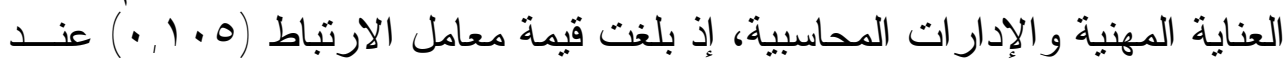




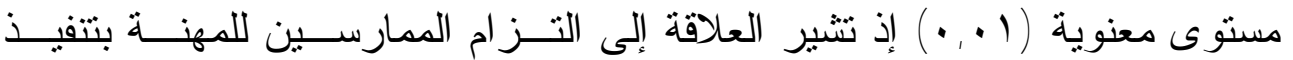

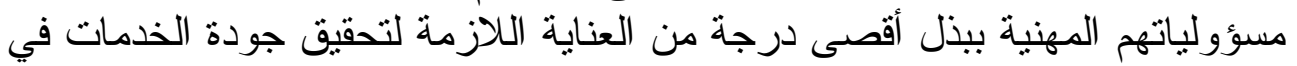

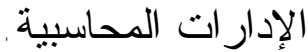

\section{r الإدلاقة بين الالتز ام بالمصداقية والإدارات المحاسبية}

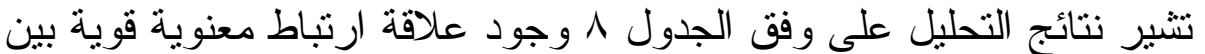

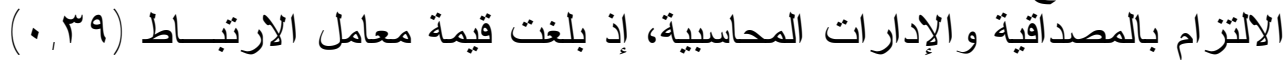

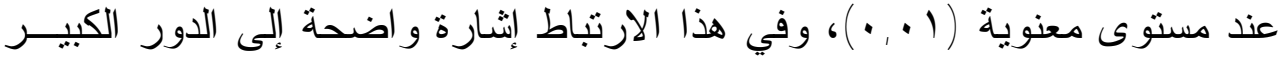

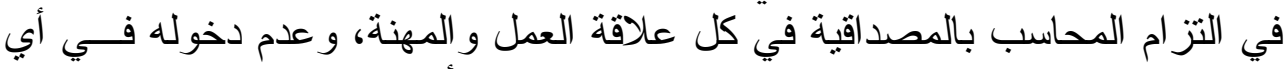

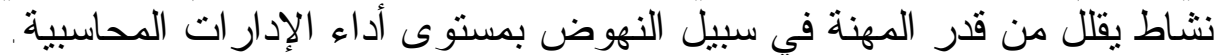

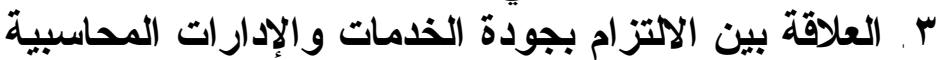

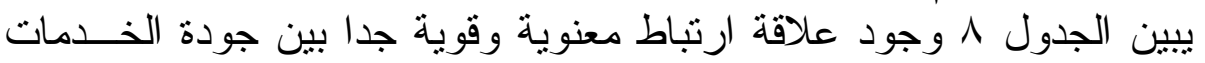

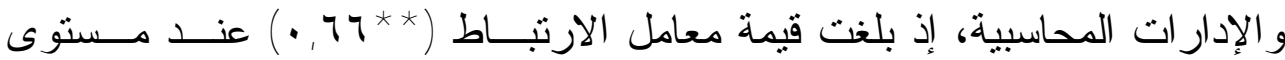

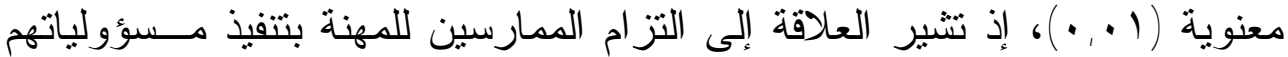

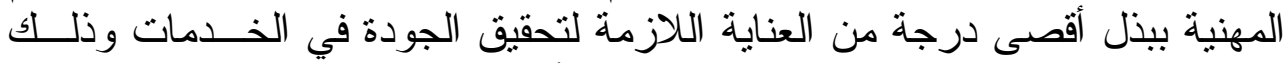

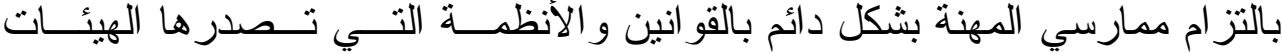

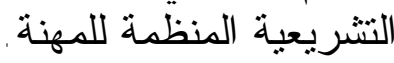

| - الاستنتاجات

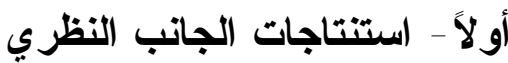

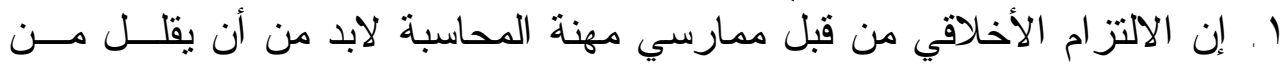
تعرض الوحدات المالية للخطر و الإدارة المحاسبية.

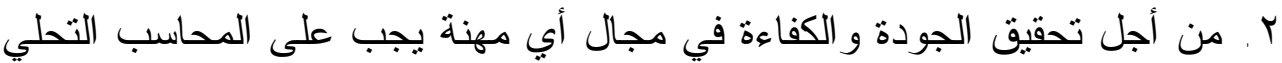

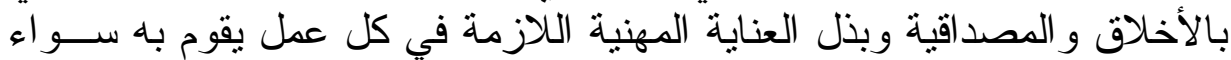

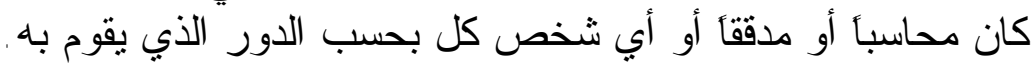

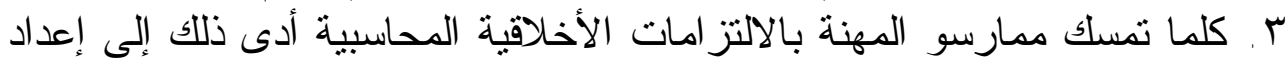

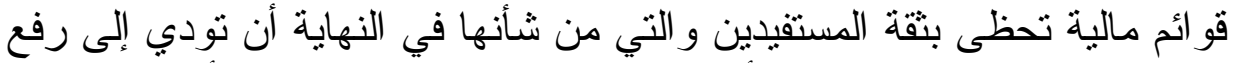

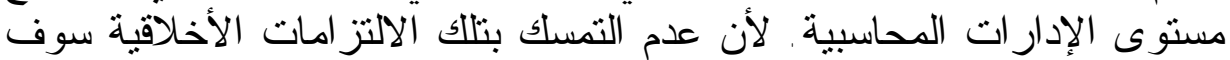
يوثر معنويأ على سمعة المهنة و الثقة التي تتمتع بها.

$$
\text { ثانياً - استنتاجات الجانب العملي }
$$

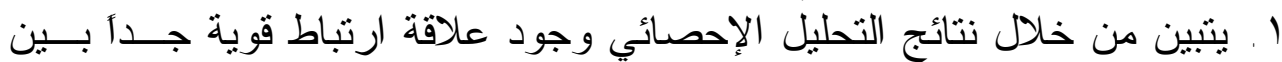

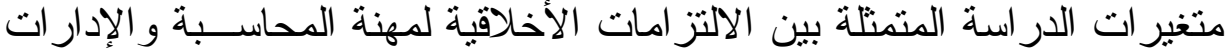

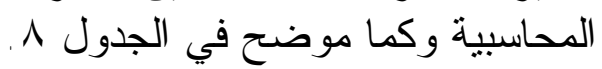
r. وجود علاقة ارتباط معنوية بين الالتز ام ببذل العناية المهنية اللازمة و الإدارات 
الليلة [1. [1]

- وجود علاقة ارتباط معنوية بين الالتز ام بالمصداقية و الإدار ات المحاسبية.

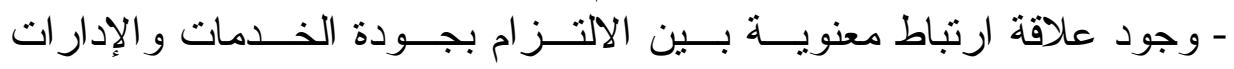
المحاسبية.

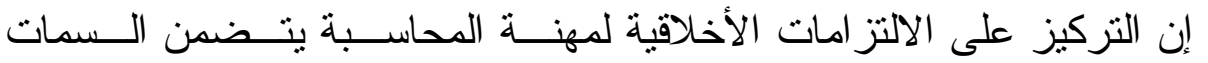

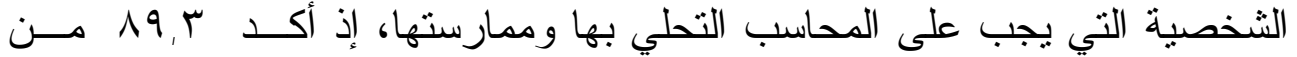
أفر اد العينة على ضرورة قيام المحاسب بحل كل مشاكل وصعوبات العمل بعنايـــة

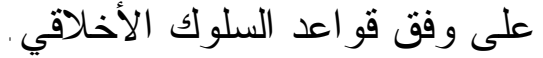

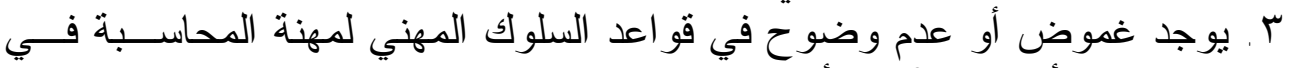

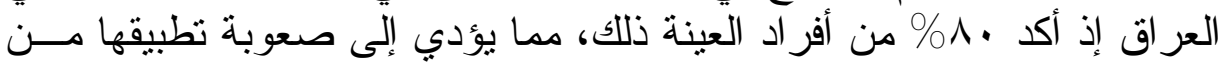

قبل المحاسبين.

\section{التوصيات}

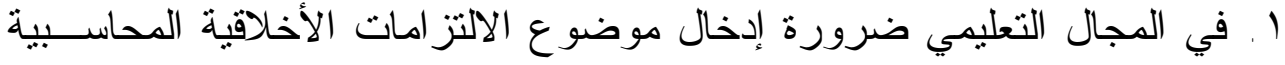

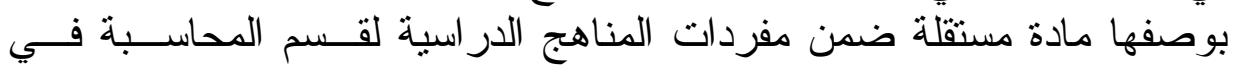

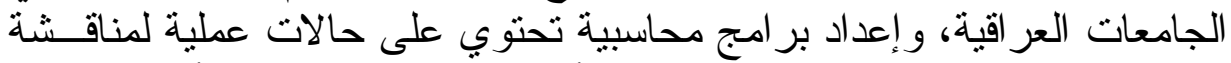

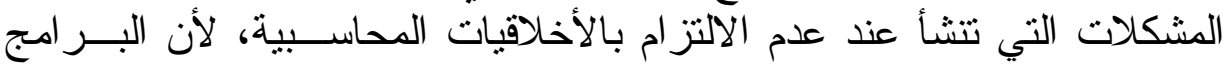
المحاسبية سوف تساعد الطلبة على تطوير مهار اتهم المهنية في حل المشكلات.

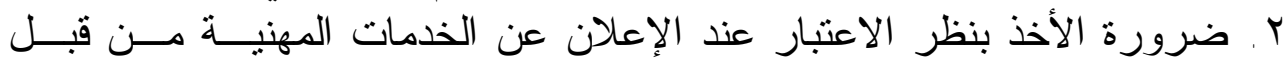

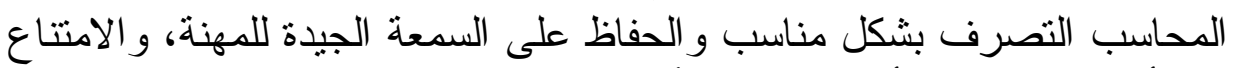

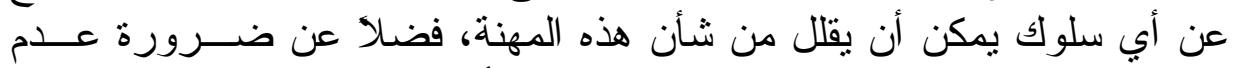

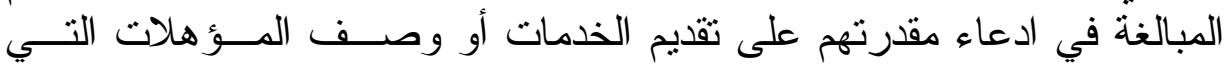

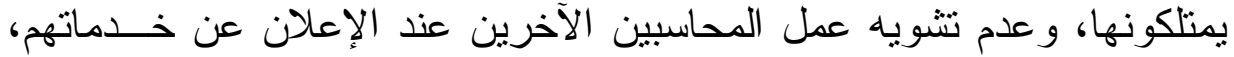

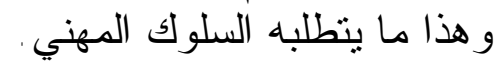

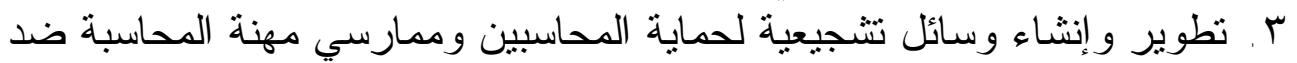

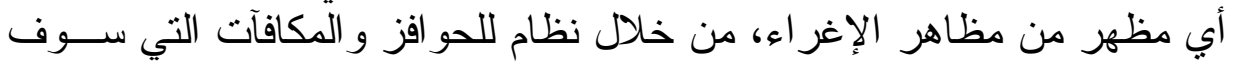

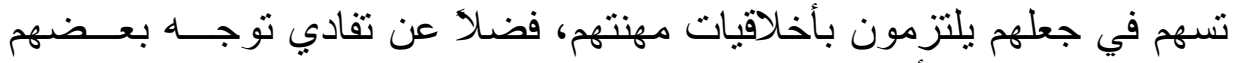
نحو السلّوك غير الأخلاقي في سبيل تحقيق الجودة في عملهم .

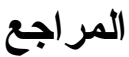 \\ أولاً - المراجع باللغة العربية}

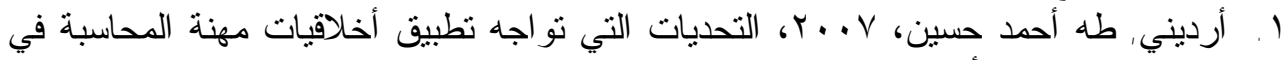

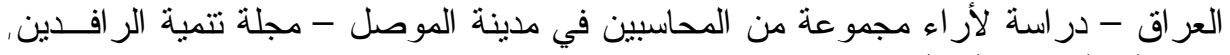

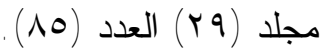

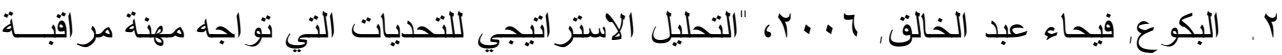

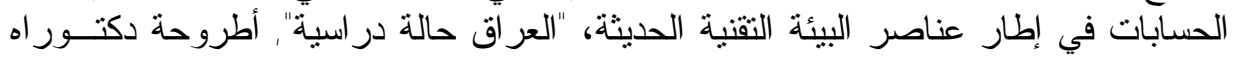

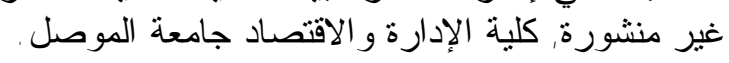




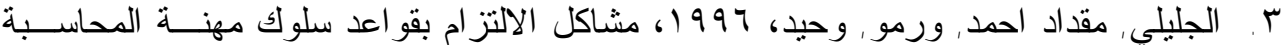

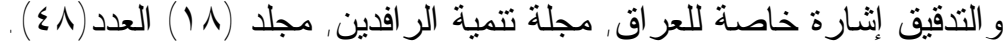

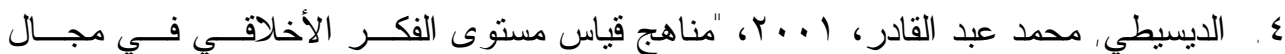

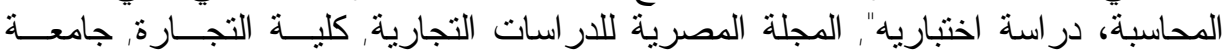

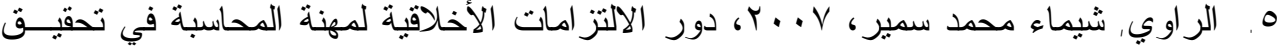

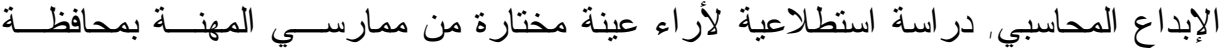

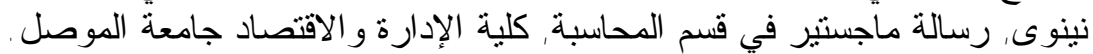

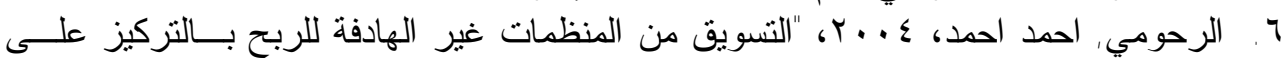

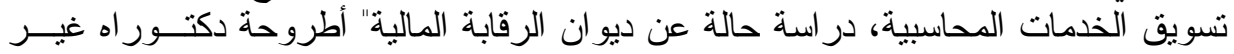

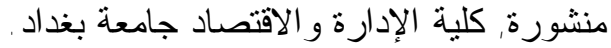

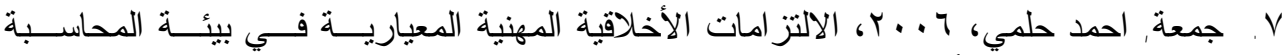
العربية، دليل من الأردن, المؤتمر العلمي السنوي السادس, كلية الاقتصاد و العلوم الإداريــة. جامعة الزينونة .

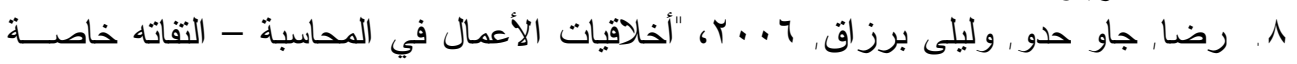

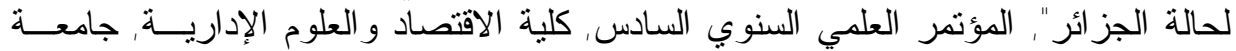

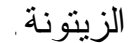

9 . . الثير ازي, عباس مهدي, •9919، نظرية محاسبية, منشور ات ذات السلاسل, الكويت.

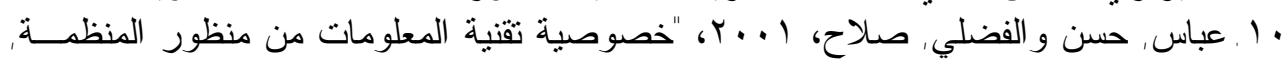

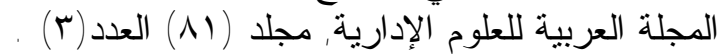

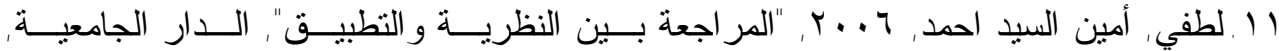

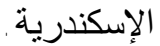

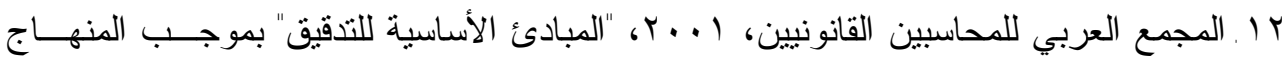

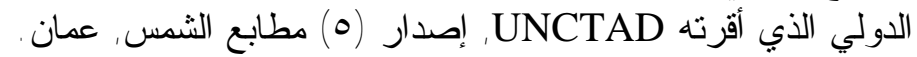

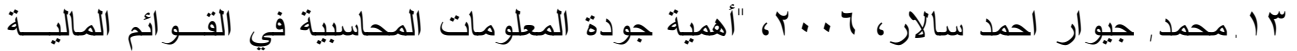

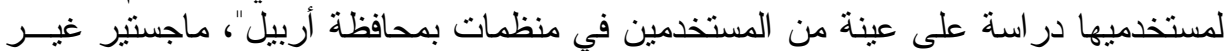
منشورة, كلية الإدارة و الاقتصاد جامعة الموصن المعل.

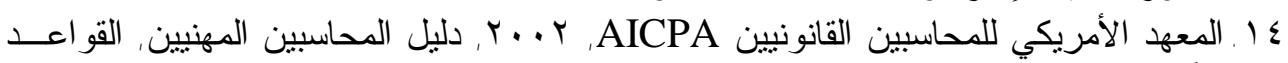
الأخلاقية, ترجمة جمعية مدققي الحسابات القانونيين الفلسطينية.

\section{ثانياً - المر اجع باللغة الأجنبية}

1. IFAC, 2005 Hand book of International Auditing ,Assurance and Ethics Pronouncements 2005 ED ,International Federation of Accountants Jan . 